\title{
Curcumin Suppresses Metastasis via Sp-1, FAK Inhibition, and E-Cadherin Upregulation in Colorectal Cancer
}

\author{
Chun-Chieh Chen, ${ }^{1,2}$ Munisamy Sureshbabul, ${ }^{1,2}$ Huei-Wen Chen, ${ }^{2,3}$ Yu-Shuang Lin, \\ Jen-Yi Lee, ${ }^{3}$ Qi-Sheng Hong, ${ }^{1,2}$ Ya-Chien Yang, ${ }^{1,4}$ and Sung-Liang Yu ${ }^{1,2,4,5,6}$ \\ ${ }^{1}$ Department of Clinical Laboratory Sciences and Medical Biotechnology, College of Medicine, National Taiwan University, \\ Taipei 100, Taiwan \\ ${ }^{2}$ Center of Genomic Medicine, National Taiwan University, Taipei 100, Taiwan \\ ${ }^{3}$ Graduate Institute of Toxicology, College of Medicine, National Taiwan University, Taipei 100, Taiwan \\ ${ }^{4}$ Department of Laboratory Medicine, National Taiwan University Hospital, Taipei 100, Taiwan \\ ${ }^{5}$ Graduate Institute of Pathology, College of Medicine, National Taiwan University, Taipei 100, Taiwan \\ ${ }^{6}$ Center for Optoelectronic Biomedicine, College of Medicine, National Taiwan University, Taipei 100, Taiwan
}

Correspondence should be addressed to Sung-Liang Yu; slyu@ntu.edu.tw

Received 12 April 2013; Accepted 17 June 2013

Academic Editor: Hyung-In Moon

Copyright (C) 2013 Chun-Chieh Chen et al. This is an open access article distributed under the Creative Commons Attribution License, which permits unrestricted use, distribution, and reproduction in any medium, provided the original work is properly cited.

Colorectal cancer (CRC) is a serious public health problem that results due to changes of diet and various environmental stress factors in the world. Curcumin is a traditional medicine used for treatment of a wide variety of tumors. However, antimetastasis mechanism of curcumin on CRC has not yet been completely investigated. Here, we explored the underlying molecular mechanisms of curcumin on metastasis of CRC cells in vitro and in vivo. Curcumin significantly inhibits cell migration, invasion, and colony formation in vitro and reduces tumor growth and liver metastasis in vivo. We found that curcumin suppresses Sp-1 transcriptional activity and Sp-1 regulated genes including ADEM10, calmodulin, EPHB2, HDAC4, and SEPP1 in CRC cells. Curcumin inhibits focal adhesion kinase (FAK) phosphorylation and enhances the expressions of several extracellular matrix components which play a critical role in invasion and metastasis. Curcumin reduces CD24 expression in a dose-dependent manner in CRC cells. Moreover, E-cadherin expression is upregulated by curcumin and serves as an inhibitor of EMT. These results suggest that curcumin executes its antimetastasis function through downregulation of Sp-1, FAK, and CD24 and by promoting E-cadherin expression in CRC cells.

\section{Introduction}

Globally most of the cancers associated with mortality and morbidity arise from metastatic spread of primary tumors. Colorectal cancer (CRC) is the third most prevalent malignancy in human after breast and lung cancers, and statistics suggest that six million people are suffering from CRC and more than 63,900 deaths are expected every year. In 2012, 143,900 people were diagnosed with CRC, and death rate is expected to be 51.690 from CRC in the United States [1]. Recent data suggests that mortality rate from CRC is increasing in Asian countries, particularly in Taiwan, where more than 10,000 patients were diagnosed to be suffering from CRC $[2,3]$. CRC affects liver, lung, colon, and rectum, in aged people due to change of their life style and dietary habits. However, the etiology of CRC has not yet been understood clearly. Alternation of normal cells into tumor cells requires several biochemical and phenotype changes in tissue and then spread of individual cell or a small cluster of cancer cells from primary site into distant organs. Mechanism of metastasis is a critical process due to migration of tumor cells from original site into surrounding tissue. Metastasis is classified into at least five different steps: (i) invasion and migration, (ii) intravasation into lymphatic system, (iii) circulation, (iv) extravasation, and (v) colonization. All these steps are mediated by multiple factors such as: growth factors, proteolysis degradation, cell-cell adhesion, cytoskeleton remodeling, and expression of genes which are known to 
be ultimately involved in metastasis of tumor cells [4]. Transcription factors and their downstream genes involve the modulation of signal transduction pathways leading to either upregulation or downregulation of specific genes expression involved in tumor progression [5-7]. Noteworthy, the focal adhesive kinase (FAK) plays an important role in cytoskeleton remodeling and in regulating the tumor cell invasiveness and metastasis [8, 9]. Moreover, interactions between the cell surface molecule and metalloproteinases (MMPs) require tumor cell invasion and angiogenesis [10]. Downregulation of cell adhesive molecules leads to disruption of adherent junctions resulting in change of epithelial cell morphology, and modulation of phenotype changes epithelial to mesenchymal transition (EMT) [11]. Several factors such as transcription factors, focal adhesion molecule, and cell surface receptors are associated with tumor metastasis. These factors either directly or indirectly participate in the up- or downregulation of specific genes expression in tumor metastasis. Transcription factors associated with housekeeping genes expression are known to be involved in tumor angiogenesis and cell differentiation and to mediate focal adhesive molecule that plays prime role in tumor cell migration and invasion.

Sp-1, a transcription factor that is expressed highly in breast cancer, gastric and thyroid carcinoma cells compared to normal cells, interacts with coactivators and corepressors and thereby activates multiple biological functions such as: cell cycle and tumorigenesis. It also mediates interaction with nuclear factors, protein-protein interaction, and sequencespecific DNA binding [12]. Sp-1 is associated with housekeeping genes expression including vascular epithelial growth factors (VEGF), urokinase plasminogen activator (uPA), urokinase plasminogen activator receptor (UPAR), and epithelial growth factor receptor (EGFR) which are mediated in tumor angiogenesis and cell differentiation [5-7]. Sp-1 also serves as a docking site for binding with CD11b which causes transcriptional activity [13] and is also essential for FAK activation of Krüppel- like factor 8 (KLF8) promoter in human ovarian cancer cells [14]. Acetylation of Sp-1 could modulate Bak and p21 promoter binding activity associated with cell cycle arrest and apoptosis in colon cell lines [15]. These studies implicate that tumor angiogenesis or invasion is associated with Sp1 activities and its downstream genes expression, and also Sp-1 mediates focal adhesive molecule including FAK which plays prime role in tumor cell migration. It is well known that FAK, a nonreceptor tyrosine kinase protein localized at focal adhesion, serves as a scaffold molecule to mediate several biological functions including cell migration, focal adhesion complex formation. FAK is more highly expressed in breast, ovarian, and CRC metastasis than in normal cells and is activated by its phosphorylation sites thereby interacting with other signals to promote cell migration [16]. It serves as a platform for interaction of ECM and integrins and regulates Src, p130CAS and Grb2, Grb7, and phosphatidylinositol 3kinase (PI3K) for cell migration and cell cycle progression [9]. It was reported that cell surface molecule such as CD24 mediates c-Src kinase for FAK phosphorylation and paxillin which in turn promote integrin-dependent adhesion and tumor cell invasion and metastasis [17]. This suggests that FAK regulates multiple intracellular signals and cell surface molecule for tumor cell migration. Cell surface molecules regulate the cytoskeleton remodeling and promote cell-matrix adhesion and cell migration, cell invasion, and metastasis. CD24 is one of the major cell surface glycosylated proteins which function as an adhesive molecules of tumor cells [18]. The downregulation of CD24 reduces STAT and FAK activity, decreases cell proliferation, metastasis in human tumor [19], and reduces E-cadherin (E-cad) expression in cultured epithelial cells [20]. These studies suggest that CD24 expression associates with FAK and E-cad function and facilitates the passage of tumor cells in blood stream during metastasis.

It has been reported that loss of cell-cell adhesion is the major process that reduces tumor cell adhesiveness leading to tumor cell growth, invasion, and metastasis [21]. E-cad is a prime component of adherence junction and regulates the tumor cell progression, migration, invasion, and metastasis through maintenance of cell-cell contacts. Noteworthy, the E$\mathrm{cad} / \beta$-catenin complex stabilizes the cell adherence junctions and also prevents transactivation of gene expression. The $\beta$ catenin dissociates from E-cad and then translocates into nucleus from cytoplasm, where it binds with LEF1 undergoing transactivation [22]. Downregulation of E-cad could lead to increased $\beta$-catenin in cytoplasm and is responsible for loss of cell-cell contacts between epithelial cells which in turn change morphology and adhesiveness of EMT [11]. It is well known that epithelial cells are tightly connected with each other by intracellular junctions to avoid cell motility, once epithelial cells lose polarity and intracellular connections and then lead to cell motility and cancer metastasis. Curcumin (CUR) is a hydrophobic polyphenol molecule which persists as a keto-enol tautomerism, and its covalent binding, hydrophobic interactions, and hydrogen bonding play prime role in multiple biological and pharmacological functions [23]. CUR prevents breast, lung, pancreas, and prostate cancer cell proliferation and also exhibits anti-inflammation, antioxidant, antimicrobial, and wound healing activities. CUR interacts with multiple receptors, transcriptional factor, and cytokines and also reduces cell proliferation, angiogenesis, and metastasis [24-28]. Previous studies have implicated that CUR prevents cancer cells migration, invasion, and metastasis through inhibition of PKC, FAK, NF- $\kappa \mathrm{B}, \mathrm{p} 65$, RhoA, MMP-2, and MMP-7 gene expressions [29]. We have reported that CUR inhibits lung cell invasion and metastasis via upregulation of DnaJ-like heat shock protein 40 (HLJ1) expression and activation of JNK/JunD signaling pathway [27] and also exhibited antitumor caliber in human lung adenocarcinoma cells [28]. Several studies have implicated that CUR mediates the growth factors, cytokine, and transcriptional factors for suppression of tumor apoptosis, cell proliferation, invasion, and metastasis. However, to date there is no direct evidence for CUR effect on transcription factor, focal adhesion molecule, and cell-cell adhesion component for inhibition of tumor metastasis. In this study, we evaluated CUR role on Sp-1 transcription factor, cell adhesion component FAK, CD24 signals, and E-cad expression in CRC cell lines. Inhibition of $\mathrm{Sp}-1$ and promotion of E-cad expression may be an effective strategy for successful treatment of CUR to resistance of CRC metastasis, and CUR is thought to be 
a potential chemopreventive and therapeutic drug especially in colorectal cancer.

\section{Materials and Methods}

2.1. Cell Lines and Cell Culture. The human colon cancer cell lines from NCI-60 panel, including HCT-116, HT-29, HCT-15, HCC-2998, Colo205, Km-12, and SW-620 cells, were maintained in RPMI-1640 medium (Gibco, Grand Island, NY) supplemented with $10 \%$ fetal bovine serum ((FBS) Gibco, Grand Island, NY), 1\% Antibiotic-Antimycotic (Life Technologies, Carlsbad, CA), 10 mM HEPES (Sigma-Aldrich, St. Louis, MO), and $2 \mathrm{mM}$ L-glutamine (Life Technologies, Carlsbad, CA) at $37^{\circ} \mathrm{C}$, in humidified atmosphere of $5 \% \mathrm{CO}_{2}$.

2.2. Cell Viability Assay. CRC cells were seeded at $1 \times 10^{4}$ cells per well in a 96-well plate and incubated overnight. Then, the cells were treated with different concentrations of curcumin $(0,1,5,10,15,20,25,30$, and $50 \mu \mathrm{M})$ for $24 \mathrm{~h}$. Medium was then removed, and $100 \mu \mathrm{L}$ of $0.5 \mathrm{mg} / \mathrm{mL}$ MTT reagent (Thiazolyl Blue Tetrazolium Bromide; Sigma-Aldrich, St. Louis, MO) was added to each well and reincubated at $37^{\circ} \mathrm{C}$ incubator for $1.5 \mathrm{~h}$. The MTT reagent was then aspired, and $100 \mu \mathrm{L}$ DMSO was added to dissolve the Formazan crystal formed by living cells. Absorbance was measured at $570 \mathrm{~nm}$ wavelengths by using an ELISA plate reader.

2.3. Wound Healing Assay. $1 \times 10^{6}$ cells were seeded in each well of 6-well plate and incubate at $37^{\circ} \mathrm{C}$ incubator for $24 \mathrm{~h}$. The confluent cell monolayers were wounded by a Q-tip. After washing once with PBS, the wells were added with RPMI medium which contained different concentrations of curcumin $(0,5,10$, and $20 \mu \mathrm{M})$. Time-lapse images were acquired every $30 \mathrm{~min}$ on a Zeiss Axiovert $200 \mathrm{M}$ microscope covered with an incubation system (Carl Zeiss Microimaging, Oberkochen, Germany) for $24 \mathrm{~h}$.

2.4. Matrigel Invasion Assay. In invasion assay, transwell membranes ( $8 \mu \mathrm{m}$ pore size, $6.5 \mathrm{~mm}$ diameter; Corning Costar Corporation, Cambridge, MA) were coated with matrigel $(2.5 \mathrm{mg} / \mathrm{ml}$; BD Biosciences Discovery Labware, Bedford, MA), which was diluted in serum-free RPMI medium. $5 \times 10^{5}$ cells seeded onto the matrigel with different concentrations of curcumin $(0-20 \mu \mathrm{M})$ in serum-free RPMI medium. Lower wells of the transwells contained different concentrations of curcumin in RPMI with $10 \%$ FBS. After $18 \mathrm{~h}$ incubation, membranes were swabbed with a Q-tip, fixed with methanol, and stained with Giemsa solution. Finally, the invasive cells were counted under microscopy.

2.5. Transwell Migration Assay. In migration assay, $3 \times 10^{5}$ cells were seeded onto the top of transwells with different concentrations of curcumin $(0-20 \mathrm{M})$ in serum-free RPMI medium and incubated for $12 \mathrm{~h}$. Lower wells of the transwells contained different concentrations of curcumin in RPMI with $10 \%$ FBS. After $12 \mathrm{~h}$ incubation, membranes were swabbed with a Q-tip, fixed with methanol, and stained with Giemsa solution. Cells migrated to the lower surface were counted under microscopy.
2.6. Anchorage-Independent Colony Formation Assay. For anchorage-independent colony formation assay, six-well plates were first layered with $1 \mathrm{~mL} 0.7 \%$ low-melting point agarose in PBS. In the second layer, 500 HCT-116 cells pretreated with different concentrations of curcumin $(0,5,10$, and $20 \mu \mathrm{M}$ ) for $24 \mathrm{~h}$ were suspended in $1 \mathrm{ml}$ RPMI containing $0.35 \%$ low-melting point agarose. $1 \mathrm{ml}$ RPMI medium was covered on the second layer. After 16 days of growth, the cells were washed in PBS, fixed in 4\% paraformaldehyde, and stained with $0.1 \%$ crystal violet. Finally, the staining solutions were disposed, PBS was added, colonies were counted by naked eye.

2.7. In Vivo Mouse Model. For in vivo metastasis assay, sixweek-old severe combined immunodeficiency (SCID) mice supplied by the animal center in the College of Medicine National Taiwan University (Taipei, Taiwan) are housed in a specific-pathogen-free facility. To generate the mouse models with liver metastases derived from human tumor cells, $1 \times 10^{6}$ HCT-116 cells were suspend in $100 \mu \mathrm{l}$ PBS and injected into the spleen of mice. After one-week recovery, the mice were randomized into control group and treatment group. Curcumin and vehicle control were administered to mice by gastric intubation at the dose of $1 \mathrm{~g} / \mathrm{kg}$ once daily for 30 days. Mice were sacrificed, and the primary tumors in spleen were harvested and weighed. The livers were also collected and weighed, and the metastatic nodules on livers were counted. Tissues were formalin fixed, paraffin embedded, and sectioned for routine hematoxylin and eosin staining.

2.8. RNA Extraction. RNAs were extracted from HCT-116 cells treated with different concentrations of curcumin $(0$, 5,10 , and $20 \mu \mathrm{M}$ ) for $24 \mathrm{~h}$. In brief, cells in a $10 \mathrm{~cm}$ dish were collected with $1 \mathrm{~mL}$ of RNA Bee reagent (Tel Test, Friendswood, TX) by a policeman. The cells in RNA bee were then added with $200 \mu \mathrm{l}$ of chloroform. After the solution was gently mixed and centrifuged, the aqueous layer was collected, mixed with the equal volume of isopropanol, incubated in the $-80^{\circ} \mathrm{C}$ refrigerator for $30 \mathrm{~min}$, and followed by centrifugation at $14,000 \times \mathrm{rpm}, 4^{\circ} \mathrm{C}$ for $15 \mathrm{~min}$. RNA pallets were washed by $75 \%$ ethanol and resolved in $50 \mu \mathrm{L}$ DEPC distilled water. The RNA concentration was determined by spectrophotometer.

2.9. Microarray Analysis. $12 \mu \mathrm{g}$ of mRNAs derived from HCT-116 cells treated with DMSO control and curcumin $(20 \mu \mathrm{M})$ for $24 \mathrm{~h}$ was used for mRNA microarray analysis. The mRNA profiles of curcumin treated and DMSO treated HCT116 cells were analyzed using Affymetrix Human Genome U133 plus 2.0 GeneChip according to the manufacturer's protocols (Santa Clara, CA, http://www.affymetrix.com/) by the Microarray Core Facility of National Research Program for Genomic Medicine of National Science Council in Taiwan. This Affymetrix GeneChip contains 54,675 probe sets to analyze the expression levels of 47,400 transcripts and variants, including 38,500 well-characterized human genes. GeneChips from the hybridization experiments were read by the Affymetrix GeneChip scanner 3000 7G, and 
raw data were processed using GC-RMA algorithm. The raw data were also analyzed by GeneSpring GX software (Silicon Genetics, Redwood City, CA). The GO biological processes of genes with greater than twofold change in curcumin treated cells compared with DMSO treated cells were analyzed using MetaCore Gene Set Enrichment Analysis (GSEA) software program (GeneGo Inc., St Joseph, $\mathrm{MI})$.

2.10. Quantitative Real-Time PCR. To confirm the expression patterns of upregulated or downregulated genes after curcumin treatment, the selected cell adhesion- and metastasisrelated genes were chosen for further analysis using quantitative real-time PCR (qRT-PCR) in a 96-well format. Briefly, all reactions were carried out in $20 \mu \mathrm{L}$ solution containing $10 \mu \mathrm{L}$ of 2X SYBR Green PCR Master Mix (Applied Biosystems, Foster City, CA). The TATA box binding protein (TBP) was quantified as an internal control using the primers described in a previous report [27]. DNA amplification was carried out using ABI 7900 Sequence Detection System (Applied Biosystems, Foster City, CA), and the detection was carried out by measuring the binding of the fluorescence dye SYBR Green I to double-stranded DNA. An amplification plot of the fluorescence signal versus cycle number was drawn. In the initial cycles of PCR, there was little change in fluorescence signal. This defined the baseline for the amplification plot. An increase in fluorescence above the baseline indicated the detection of accumulated PCR product. A fixed fluorescence threshold was set above the baseline in the exponential phase of the PCR. The parameter CT (threshold cycle) was defined as the fractional cycle number at which the fluorescence passed the fixed thresholds. The differences $(\Delta \mathrm{CT})$ between the mean values in triplicate samples of tested gene cDNA and those of TBP were calculated by Microsoft Excel, and the relative quantitation value was defined as $2-\Delta \mathrm{CT} \times \mathrm{K}$, where $\mathrm{K}$ is a constant.

2.11. Western Blot Analysis. Cells cultured in $10 \mathrm{~cm}$ dish were treated with different concentrations $(0,5,10$, and $20 \mu \mathrm{M})$ of curcumin for $24 \mathrm{~h}$. Cells were then disrupted in $500 \mu \mathrm{L}$ of lysis buffer $(50 \mathrm{mM}$ Tris/HCl, $\mathrm{pH} 7.4), 1 \%(\mathrm{v} / \mathrm{v})$ Triton $\times 100,10 \%$ glycerol, $150 \mathrm{mM} \mathrm{NaCl}, 1 \mathrm{mM}$ EDTA, $20 \mu \mathrm{g} / \mathrm{ml}$ leupeptin, $1 \mathrm{mM}$ PMSF (phenylmethylsulfonyl fluoride), $20 \mu \mathrm{g} / \mathrm{mL}$ aprotinin, and $20 \mu \mathrm{g} / \mathrm{mL}$ pepstain and centrifuged at $15,000 \times \mathrm{g}$ for $30 \mathrm{~min}$ at $4^{\circ} \mathrm{C}$. The proteins were separated on a $12 \%$ SDS polyacrylamide gel and then transferred onto nitrocellulose membranes with $400 \mathrm{~mA} / \mathrm{cm}^{2}, 100$ volts for $60 \mathrm{~min}$. The membranes were first blocked with $5 \%$ skim milk in TBST ( $0.2 \mathrm{M} \mathrm{NaCl}, 10 \mathrm{mM}$ Tris, $\mathrm{pH} 7.4$, and $0.1 \%$ Tween 20$)$ for $1 \mathrm{~h}$ and sequentially incubated with anti-FAK and anti$\beta$-actin monoclonal antibody (Life Technologies, Carlsbad, $\mathrm{CA}$ ) in $0.5 \%$ skim milk for $16 \mathrm{~h}$ at $4^{\circ} \mathrm{C}$. The membranes were then washed three times with TBST, followed by incubation with horseradish peroxidase-conjugated secondary antibody for $1 \mathrm{~h}$ at room temperature. Bound antibody was detected using the Enhanced Chemiluminescence System (Santa Cruz Biotechnologies, Santa Cruz, CA). Chemiluminescent signals were captured using the Fujifilm LAS 3000 system (Fujifilm, Tokyo, Japan).
2.12. Cell Adhesion Assay. The 96-well plate (Costar, Cambridge, MA) was coated with fibronectin $(25 \mu \mathrm{g} / \mathrm{mL})$, collagen I $(100 \mu \mathrm{M} / \mathrm{mL})$, collagen III $(100 \mu \mathrm{M} / \mathrm{mL})$, collagen IV $(100 \mu \mathrm{M} / \mathrm{mL})$, collagen IX $(100 \mu \mathrm{M} / \mathrm{mL})$, laminin $(25 \mu \mathrm{g} / \mathrm{mL})$, and negative control (BSA $40 \mu \mathrm{M} / \mathrm{mL}$ ) at $4^{\circ} \mathrm{C}$ overnight. After removing these coating extracellular matrix (ECM), the plate was blocked by $1 \% \mathrm{BSA}$ at $4^{\circ} \mathrm{C}$ in $\mathrm{CO}_{2}$ incubator for $4 \mathrm{~h}$. HCT116 cells were pretreated with different concentrations of curcumin $(0,5,10$, and $20 \mu \mathrm{M})$ for $24 \mathrm{~h}$ and then changed into serum-free medium for $30 \mathrm{~min}$. Cells were trypsinized, and cell numbers were adjusted to $2 \times 10^{5}$ cells $/ \mathrm{ml}$ in serum-free medium. After removing the blocking buffer, $2 \times 10^{4}$ cells in $100 \mu \mathrm{l}$ serum-free medium were added in each well of the 96 well plate. The plate was incubated in $\mathrm{CO}_{2}$ incubator at $37^{\circ} \mathrm{C}$ for 60 minutes. Adhesive cells were washed with washing buffer (PBS) 2-3 times, fixed with $4 \%$ paraformaldehyde, and stained with Hoechst dye. Images of cells in each well of the 96-well plate were acquired, and the number of adhesive cells was calculated by High Content System (HCS).

2.13. Sp-1 Luciferase Assay. $5 \times 10^{5} 293 \mathrm{~T}$ cells in 6-well plate were transient transfected with Sp-1 reporter plasmids $(2 \mu \mathrm{g})$ and Renilla control vectors $(0.2 \mu \mathrm{g})$. After $24 \mathrm{~h}$, the cells were treated with different concentrations of curcumin $(0,5,10$, and $20 \mu \mathrm{M}$ ) for further $24 \mathrm{~h}$. Then, the activities of firefly and Renilla luciferase were quantified by dual luciferase assay system (Promega, Madison, WI). The transcriptional activity of Sp-1 was expressed as a ratio of firefly: Renilla luciferase activity.

\section{Results}

3.1. Curcumin Inhibits Proliferation, Migration, Invasion, and Colony Formation of CRC Cell Lines. The current study was conducted to delineate the underlying molecular mechanism of CUR on CRC metastasis. First, we attempted to observe the biological effect of CUR on CRC cell viability. The CRC cell lines (HCT-116, HT-29, Colo-205, HCT-15, KM-12, SW620, and HCC2998) were exposed to different concentrations of CUR for $24 \mathrm{~h}$, and performed MTT assay (Figure 1(a)). The results suggest that HCT-116 cells proliferation was inhibited by CUR in a dose-dependent manner. The $\mathrm{IC}_{50}$ value of CUR was nearly $50 \mu \mathrm{M}$ in HCT-116 cell for $24 \mathrm{~h}$. We tested the cell migration ability of seven CRC cell lines using transwell migration assay. Among these, HCT-116 cell line has shown the highest migration levels, while HCT-15 and HT-29 cells displayed moderate migration levels (Figure 1(b)). Hence, we chose HCT-116 cell line and four sublethal doses of CUR (0, $5,10$, and $20 \mu \mathrm{M})$ for further investigations. The cytotoxic effect of CUR on HCT-116 cells was analyzed by trypan blue exclusion and cell counting method. The result showed no cytotoxic effect of CUR on HCT-116 cells morphology at below $20 \mu \mathrm{M}$ concentration for $24 \mathrm{~h}$ (Figure 1(c), top). The cells number and viability measured by trypan blue exclusion showed no significant change below $10 \mu \mathrm{M}$ CUR treatment but decreased to nearly $50 \%$ of control in the dose of $20 \mu \mathrm{M}$ (Figure 1(c), bottom). These data suggest that $20 \mu \mathrm{M}$ CUR had no toxicity in HCT-116 cells, and the inhibition 


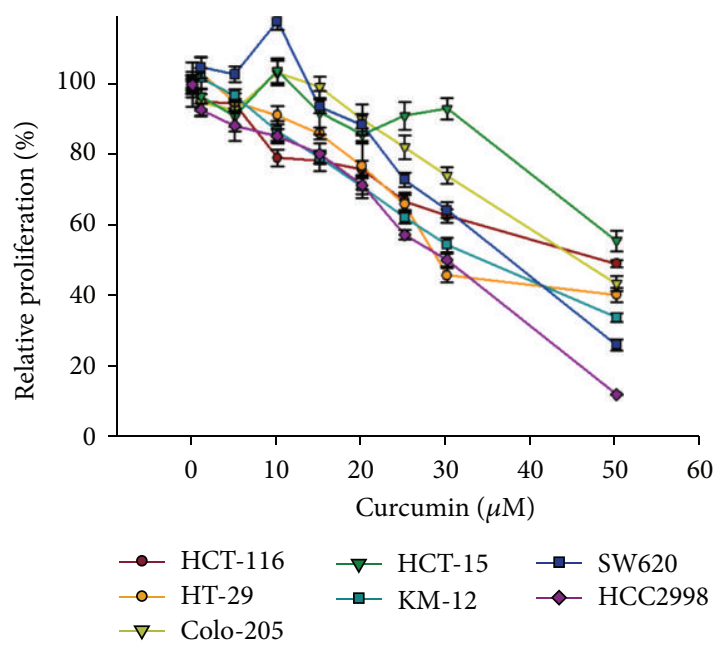

(a)
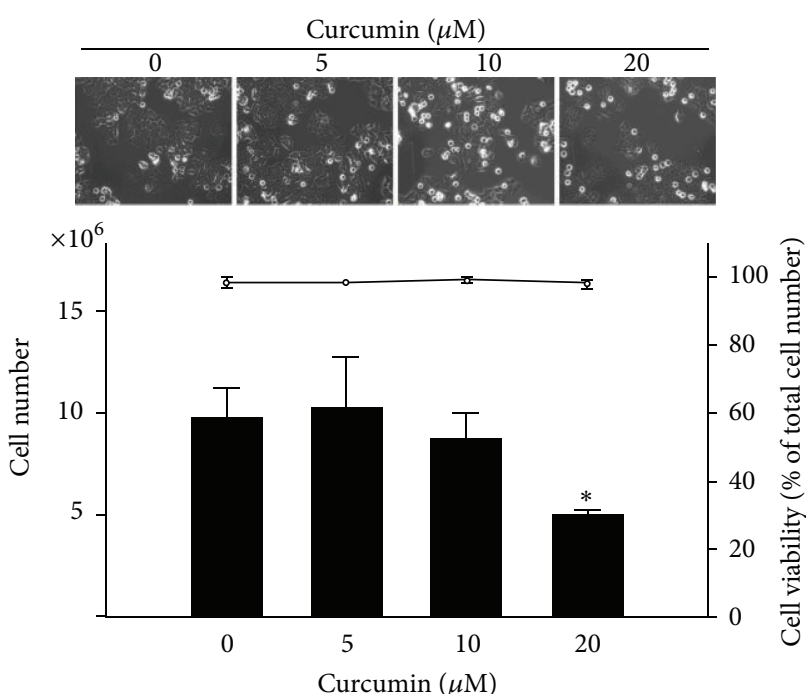

(c)

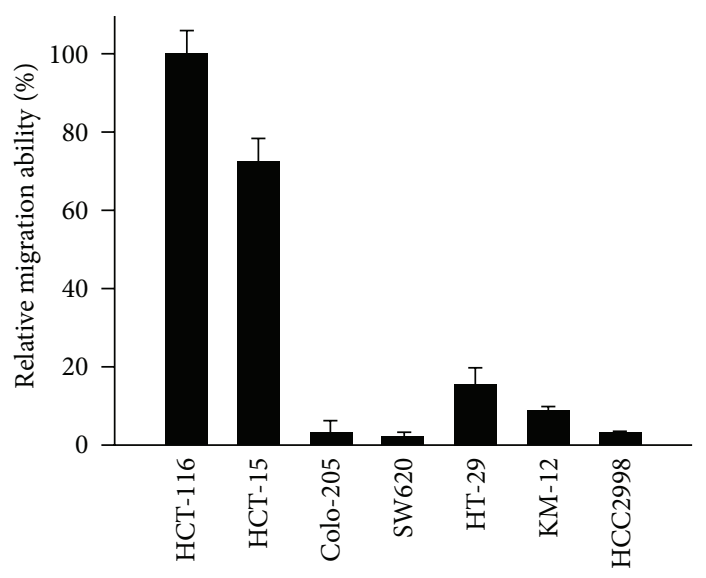

(b)

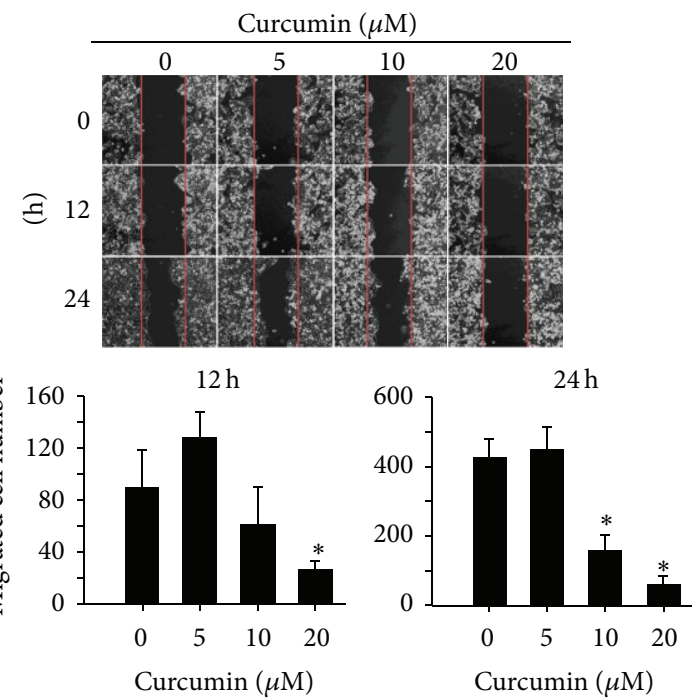

(d)
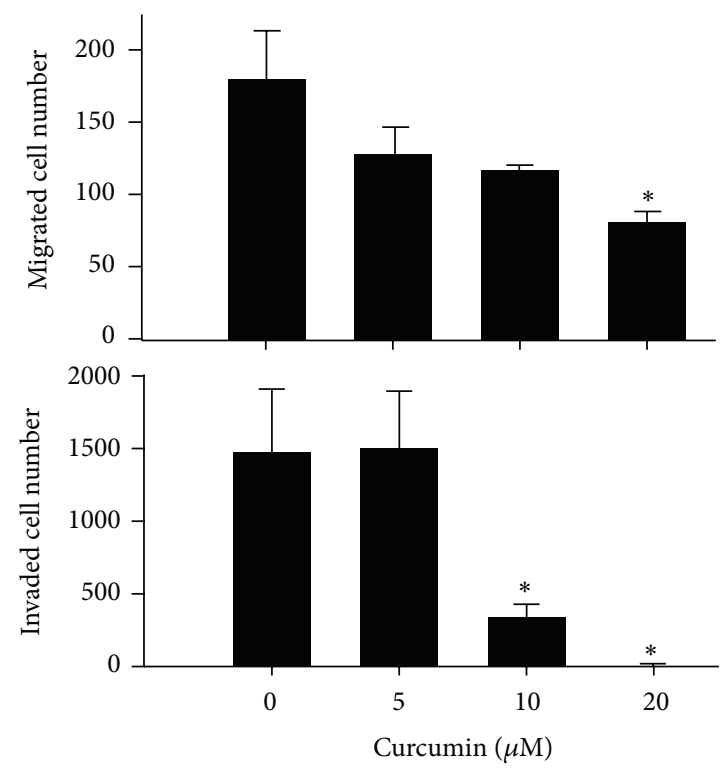

(e)

FIgUre 1: Continued. 


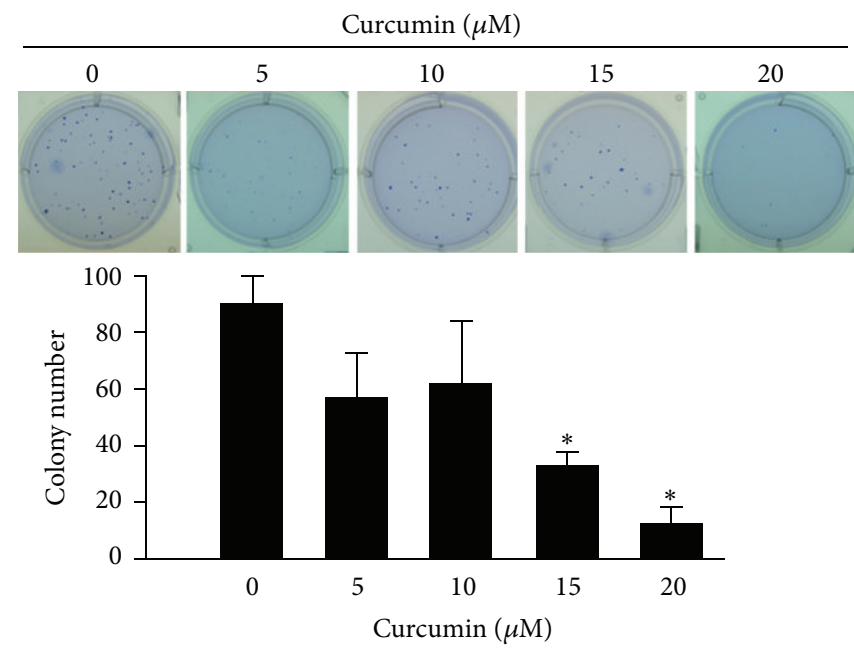

(f)

FIGURE 1: Curcumin inhibits proliferation, migration, invasion, and colony formation of CRC cell lines. (a) Proliferation inhibitory effects of curcumin on CRC cell lines. Proliferation of CRC cells was detected in HCT-116, HT-29, Colo-205, HCT-15, KM-12, SW620, and HCC2998 cell lines treated with different concentrations of curcumin $(0-50 \mu \mathrm{M})$ for $24 \mathrm{~h}$, and cell viability was determined by MTT assay. Data are presented as mean $\pm \mathrm{SD}(n=6)$. (b) Cell migration abilities of CRC cell lines. The migration-based cell motility screen was chosen to determine the relative cell motility of the 7 CRC cell lines. $5 \times 10^{5}$ cells in serum-free RPMI medium were seeded onto the top of transwells and incubated for $12 \mathrm{~h}$. Cells migrated to the lower surface were stained with GIMSA stain and counted under microscopy. Migrated cell number was normalized to migrated cells of HCT-116 cell line. Data are presented as mean \pm SD $(n=3)$. (c) Effects of curcumin on cell morphology and cell viability of HCT-116 cells. HCT-116 cells seeding in a 6-well plate were treated with different concentrations of curcumin $(0,5,10$, and $20 \mu \mathrm{M})$ for $24 \mathrm{~h}$. Images of cell morphology were captured using Zeiss Axiovert $200 \mathrm{M}$ microscope under 100x magnification (Top). After $24 \mathrm{~h}$ curcumin treatment, cell number of HCT-116 was measured using trypan blue exclusion and cell counting method (Bottom). Data are presented as mean $\pm \mathrm{SD}(n=3) .{ }^{*} P<0.05$. (d) Curcumin inhibits HCT-116 cells migration in wound healing assay. Inhibitory of curcumin on HCT-116 cells, and monolayers were wounded with a sterile $200 \mu \mathrm{l}$ pipette tip, and the cells were treated with different concentrations of curcumin $(0,5,10$, and $20 \mu \mathrm{M})$. Cells were photographed at $0 \mathrm{~h}$ and every $30 \mathrm{~min}$ to $24 \mathrm{~h}$. Images showed HCT-116 cells at 0,12 , and $24 \mathrm{~h}$ under $100 \mathrm{x}$ magnification (Top). Number of migrated cells within the wound area was counted at the time point $12 \mathrm{~h}$ (bottom left) and $24 \mathrm{~h}$ (bottom right). Data are presented as mean $\pm \mathrm{SD}(n=3) .{ }^{*} P<0.05$. (e) Curcumin suppresses HCT-116 cells motility in transwell migration and invasion assays. HCT-116 cells with serum-free media containing different concentrations of curcumin $(0,5,10$, and $20 \mu \mathrm{M})$ were seeded into the upper chamber of the transwell. Bottom wells were filled with complete media. After $12 \mathrm{~h}$ incubation, cells migrated through the transwell membrane were fixed and stained with Giemsa solution. Migrated cell numbers were counted under a light microscope with 200x magnification (Top). After $18 \mathrm{~h}$ incubation, the cells invaded through the matrigel membrane were stained and counted (Bottom). Data are presented as mean \pm $\mathrm{SD}(n=3) .{ }^{*} P<0.05$. (f) Curcumin inhibits anchorage-independent growth of HCT-116 cells in soft agar assay. 500 HCT-116 cells pretreated with different concentrations of curcumin $(0,5,10$, and $20 \mu \mathrm{M})$ for $24 \mathrm{~h}$ were suspended in growth medium containing $0.35 \%$ low-melting point agarose and seeded in 6-well plates coated with a basal layer of $0.7 \%$ low-melting point agarose. Colony assay was set up in triplicate. 2 weeks later, colonies were fixed and stained with crystal violet. Representative soft agar culture dishes showing reduced colony formation dosedependently (top). Graphic presentation of representative results of colony formation in soft agar (bottom). Data are presented as mean \pm $\mathrm{SD}(n=3) .{ }^{*} P<0.05$.

of cell proliferation was nearly $50 \%$. It is well known that metastasis is mostly dependent on tumor cell migration and invasion; therefore we are interested to observe the CUR role on HCT-116 cell migration using wound healing assay. Cells migrated into the wound area were visualized under Carl-Zeiss inverted microscope at different time points (Figure 1(d), top). The result suggests that HCT-116 cell migration was significantly inhibited by CUR (Figure $1(\mathrm{~d})$, bottom). To further confirm the effects of CUR on cell motility, we used transwell migration (Figure 1(e), top) and invasion (Figure 1(e), bottom) assay as well as zymography to determine whether cell mobility and the activities of MMP2 and MMP9 (see Supplementary Data S1 available online at http://dx.doi.org/10.1155/2013/541695) are influenced by CUR. The data revealed that CUR could dose dependently inhibit the migration (nearly 55\% of inhibition at $20 \mu \mathrm{M}$ ) and also remarkably suppress the invasion ability (nearly $89 \%$ of inhibition at $10 \mu \mathrm{M}$ and $99 \%$ of inhibition at $20 \mu \mathrm{M}$ ) and the activities of MMP2 and MMP9 of HCT-116 cells (Figure 1(e) and Supplementary Data S1). Tumor metastasis is highly dependent on cancer cell invasion and anchorageindependent tumorigenesis. To investigate whether CUR regulates the anchorage-independent colony growth of tumor cells, different concentrations of CUR $(5-20 \mu \mathrm{M})$ were used to treat HCT-116 cells for two weeks using soft agar assay, which resulted in reduced colony formation of HCT-116 cells (Figure 1(f)). Taken together, these results suggest that CUR significantly inhibits tumor cell proliferation, migration, and invasion and also suppresses colony formation in HCT-116 cells. 




(a)
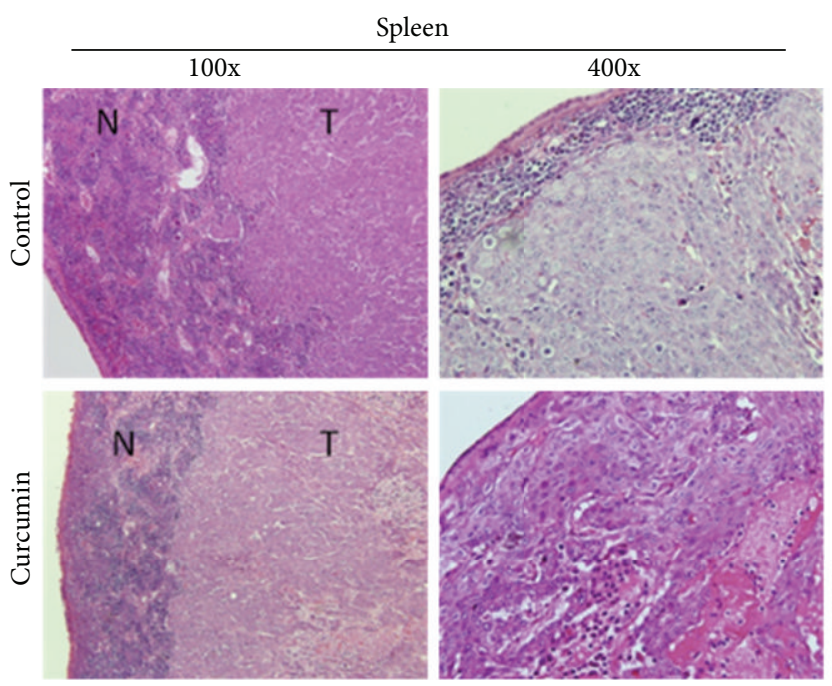
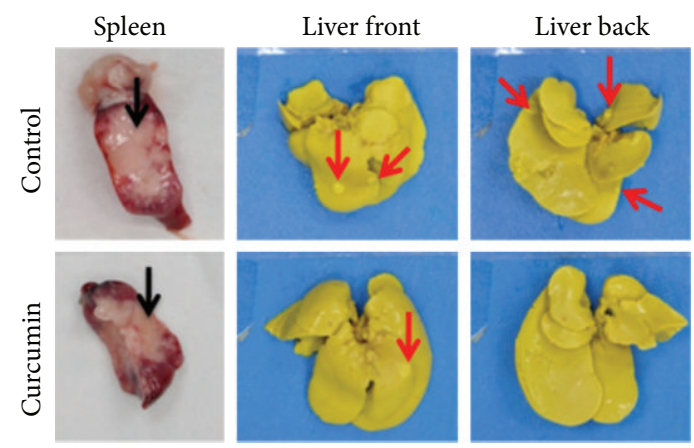

(b)

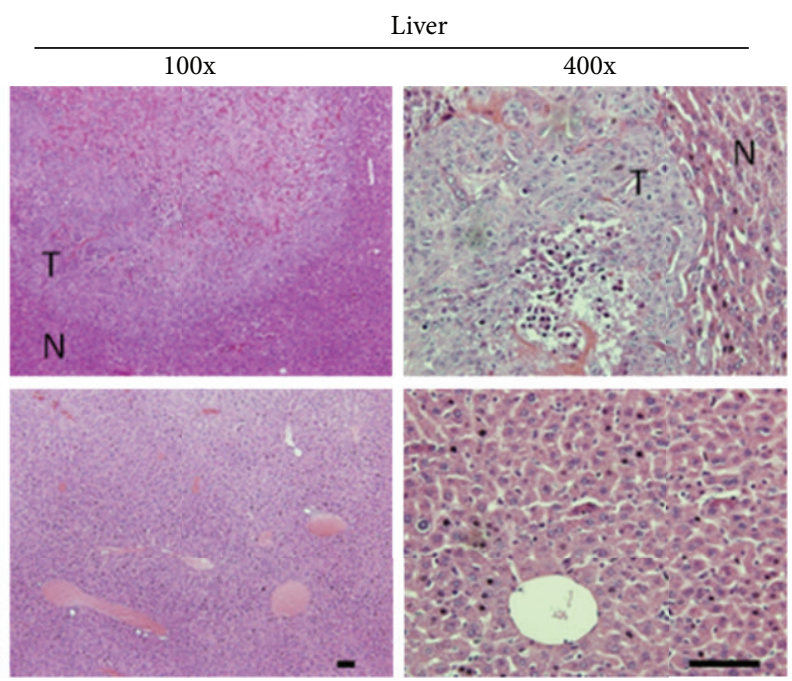

(c)

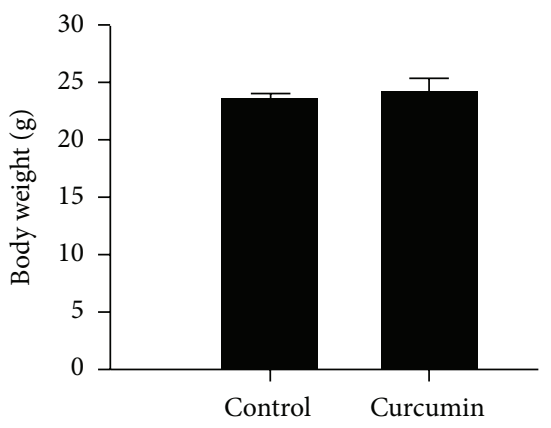

(d)

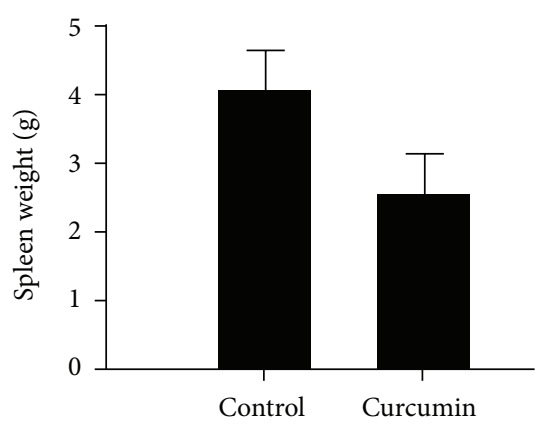

(e)

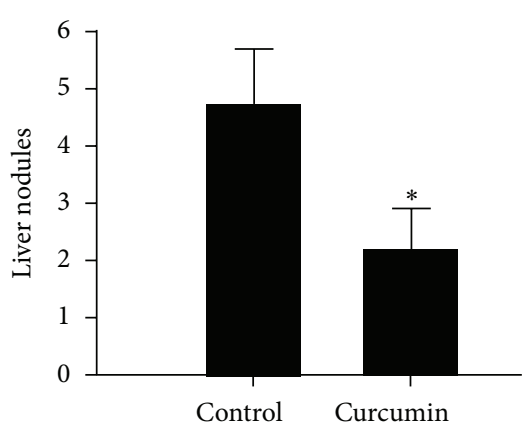

(f)

Figure 2: Curcumin inhibits tumor growth and liver metastasis in vivo. (a) Illustration of the experimental design showed the metastatic animal model. (b) Red arrow indicates the invaded tumor nodules from spleen to liver. (c) H\&E staining of paraffin-embedded tumor sections of vehicle control and curcumin treated mice. Images were acquired under an inverted microscope at 100x and 400x. T: tumor; N: normal tissue (scale bars: $10 \mu \mathrm{m}$ ). (d) The body weight of mice was not affected by CUR treatment. (e) Curcumin inhibits primary tumor growth in spleen (normalized with body weight) and (f) liver metastasis. ${ }^{*} P<0.05$.

3.2. Curcumin Inhibits Tumor Growth and Liver Metastasis In Vivo . Further, to explore whether CUR could exhibit antimetastasis effect on CRC in vivo, here, the HCT-116 cells were injected into the spleen of severe combined immunedeficient (SCID) mice, then spleen metastases were observed after one week, further mice were treated with vehicle control or CUR $(1 \mathrm{~g} / \mathrm{kg})$ for one month, finally the mice were sacrificed, and the primary tumors in spleen were harvested and weighed. The schematic illustration of in vivo experiment was shown in Figure 2(a), and the metastatic nodules on livers were indicated (Figure 2(b)). The pathologies of primary tumors and metastatic nodules were examined using $\mathrm{H} \& \mathrm{E}$ staining (Figure $2(\mathrm{c}))$. CUR treatment $(n=10)$ did not influence the body weight of mice suggesting that mice health was not affected by CUR treatment (Figure 2(d)). In this study, CUR significantly reduced primary tumor growth (Figure $2(\mathrm{e})$ ) and number of liver metastatic nodules (Figure $2(\mathrm{f}))$ compared to control group $(n=8)$. The results 


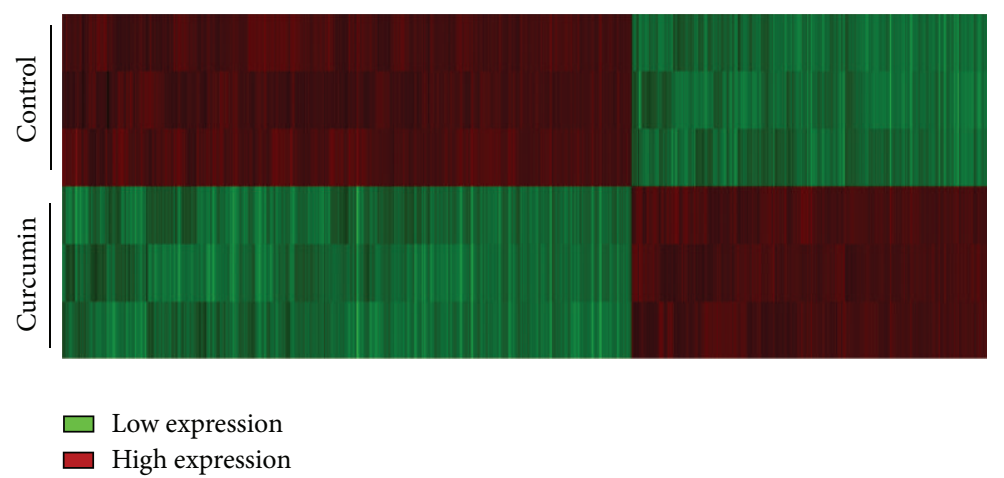

(a)

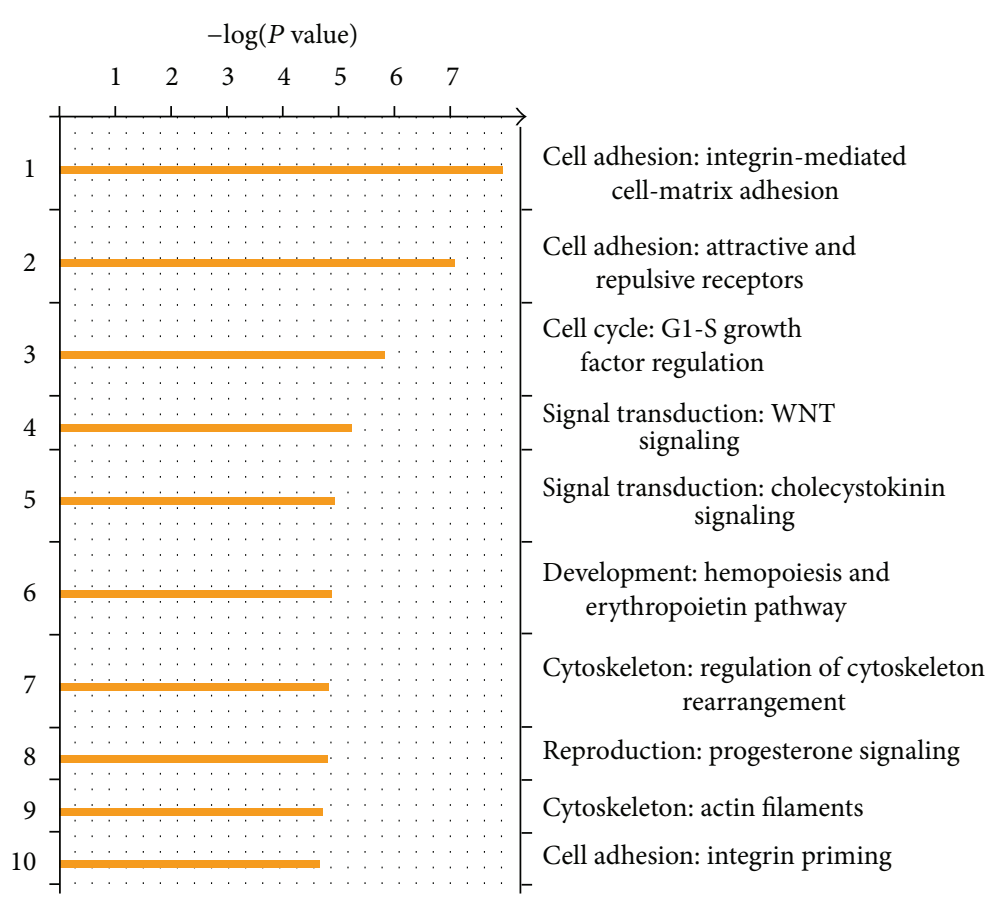

(b)

FIGURE 3: Gene expression profiles and pathway analysis of curcumin-regulated genes in HCT116 cells. (a) Affymetrix microarray was used to screen gene expression of control and curcumin treated HCT-116 cells, and the heatmap of gene expression profile was shown. (b) Curcuminregulated genes were grouped and done by pathway analysis via MetaCore software, and the pathways involved were ranked.

clearly demonstrate that CUR inhibits tumor growth and cancer metastasis of CRC in vivo model.

\subsection{Microarray Analysis of Gene Expression of HCT-116 Cells} after Treatment with Curcumin. The antimetastasis of CUR in HCT-116 cells was investigated by Affymetrix Human Genome U133 Plus 2.0 Array Chip. HCT-116 cells were treated with or without CUR $(20 \mu \mathrm{M})$ for $24 \mathrm{~h}$, and the primary analysis was done by GeneSpring GX program (Figure 3(a)). After RMA normalization and FDR correction, the functional analysis was done by MetaCore to identify the most relevant signaling pathways (Figure 3(b)). We observed 1239 genes that show more than twofold change including transcription factors, Sp-1, in HCT-116 cells in response to CUR $(20 \mu \mathrm{M})$ (Table 1$)$. These genes were categorized based on their cellular activities including the cell motility, cytoskeleton remodeling, cell adhesion, and chemotaxis signaling pathways. We selected CUR-regulated genes that were involved in tumor cell migration, invasion, and metastasis and further confirmed by qRT-PCR with specific primers (Table 2).

3.4. Curcumin Inhibits CD24 Expression in HCT-116 Cells. We investigated whether CUR induces up- or downregulation of gene expression to gain knowledge for choosing the novel gene related to CRC metastasis. Based on the microarray data we observed the following antimetastasis genes such as: AKR1B10, ARHGDIA, CD24, LEMD1, and HDAC4. Among them, we were mostly interested in CD24 which is a cancer cell surface marker associated with CRC invasiveness, differentiation, and tumor metastasis. CD24 expression was detected in microarray analysis, which consistently showed downregulation by six different probes (Figure 4(a)). We next performed $\mathrm{qRT}$-PCR to validate whether CD24 was 
TABLE 1: Transcriptional regulated networks analysis of curcumin affected genes by MetaCore.

\begin{tabular}{|c|c|c|c|c|c|}
\hline No. & Network & GO processes & $\begin{array}{c}\text { Total } \\
\text { nodes }\end{array}$ & $\begin{array}{c}\text { Seed } \\
\text { nodes }\end{array}$ & $P$ value \\
\hline 1 & Sp-1 & $\begin{array}{l}\text { Positive regulation of biological process }(45.9 \% \text {; } \\
7.506 e-25) \text {, developmental process }(54.1 \% ; 2.573 e-24) \text {, } \\
\text { positive regulation of cellular process }(42.8 \% ; 9.240 e-24) \text {, } \\
\text { anatomical structure development }(47.7 \% ; 9.685 e-22) \text {, and } \\
\text { multicellular organismal development }(49.5 \% ; 1.323 e-21)\end{array}$ & 223 & 222 & $0.000 E+00$ \\
\hline 2 & HNF4-alpha & $\begin{array}{l}\text { Cellular process }(91.7 \% ; 1.582 e-14) \text {, cellular metabolic } \\
\text { process }(66.1 \% ; 4.500 e-14) \text {, cellular macromolecule } \\
\text { metabolic process }(51.1 \% ; 7.619 e-12) \text {, regulation of } \\
\text { metabolic process }(49.4 \% ; 8.376 e-12) \text {, and regulation of } \\
\text { molecular function }(28.3 \% ; 3.538 e-11)\end{array}$ & 184 & 183 & $0.000 E+00$ \\
\hline 3 & c-Myc & $\begin{array}{l}\text { Cellular metabolic process }(78.5 \% ; 3.246 e-28) \text {, primary } \\
\text { metabolic process }(78.5 \% ; 4.624 e-28), \text { metabolic process } \\
(82.9 \% ; 4.212 e-25), \text { nitrogen compound metabolic process } \\
(56.9 \% ; 8.284 e-23) \text {, and cellular process }(96.7 \% \text {; } \\
1.088 e-22)\end{array}$ & 183 & 182 & $0.000 E+00$ \\
\hline 4 & CREB1 & $\begin{array}{l}\text { Positive regulation of biological process }(51.6 \% \text {; } \\
4.179 e-19) \text {, regulation of cellular process }(82.8 \% \text {; } \\
4.212 e-18) \text {, regulation of biological process }(83.6 \% \text {; } \\
1.163 e-16), \text { biological regulation }(85.2 \% ; 2.132 e-16) \text {, and } \\
\text { positive regulation of cellular process }(45.1 \% ; 1.518 e-15)\end{array}$ & 122 & 121 & $1.260 E-213$ \\
\hline 5 & p53 & $\begin{array}{l}\text { Regulation of cell cycle }(24.4 \% ; 6.529 e-16) \text {, negative } \\
\text { regulation of biological process }(44.5 \% ; 2.372 e-15), \\
\text { negative regulation of cellular process }(42.0 \% ; 7.092 e-15), \\
\text { anatomical structure morphogenesis }(34.5 \% ; 9.440 e-14), \\
\text { and positive regulation of biological process }(45.4 \% \text {; } \\
1.493 e-13)\end{array}$ & 120 & 119 & $5.020 E-210$ \\
\hline 6 & ESR1 (nuclear) & $\begin{array}{l}\text { Positive regulation of biological process }(51.7 \% \text {; } \\
1.418 e-18) \text {, positive regulation of cellular process }(49.2 \% \text {; } \\
1.607 e-18) \text {, regulation of metabolic process }(61.9 \% \text {; } \\
1.599 e-16), \text { regulation of macromolecule metabolic } \\
\text { process }(54.2 \% ; 1.174 e-15) \text {, and negative regulation of } \\
\text { biological process }(44.9 \% ; 1.529 e-15)\end{array}$ & 118 & 117 & $1.990 E-206$ \\
\hline 7 & AP-1 & $\begin{array}{l}\text { Negative regulation of biological process }(55.3 \% \text {; } \\
3.643 e-22) \text {, negative regulation of cellular process }(51.5 \% \text {; } \\
1.486 e-20) \text {, response to stress }(53.4 \% ; 3.747 e-20) \text {, positive } \\
\text { regulation of cellular process }(52.4 \% ; 5.642 e-19) \text {, and } \\
\text { positive regulation of biological process }(52.4 \% ; 5.840 e-17)\end{array}$ & 104 & 104 & $4.170 E-185$ \\
\hline 8 & EGR1 & $\begin{array}{l}\text { Regulation of molecular function }(45.5 \% ; 4.341 e-19) \text {, } \\
\text { positive regulation of biological process }(54.5 \% \text {; } \\
3.071 e-18) \text {, developmental process }(61.4 \% ; 7.639 e-17) \text {, } \\
\text { anatomical structure development }(56.4 \% ; 1.693 e-16) \text {, and } \\
\text { positive regulation of cellular process }(49.5 \% ; 2.508 e-16)\end{array}$ & 101 & 100 & $6.280 E-176$ \\
\hline 9 & $N F-\kappa B$ & $\begin{array}{l}\text { Positive regulation of cellular process }(53.2 \% ; 5.019 e-18) \text {, } \\
\text { negative regulation of biological process }(52.1 \% \text {; } \\
8.477 e-18) \text {, positive regulation of biological process } \\
(55.3 \% ; 1.013 e-17) \text {, response to stress }(52.1 \% ; 1.554 e-17) \text {, } \\
\text { and regulation of programmed cell death }(36.2 \% \text {; } \\
3.551 e-17)\end{array}$ & 96 & 95 & $5.510 E-167$ \\
\hline 10 & $\mathrm{E} 2 \mathrm{~F} 1$ & $\begin{array}{l}\text { Regulation of cell cycle }(36.3 \% ; 5.835 e-24) \text {, regulation of } \\
\text { macromolecule metabolic process }(69.2 \% ; 2.822 e-23), \\
\text { regulation of primary metabolic process }(70.3 \% \text {; } \\
1.619 e-22) \text {, regulation of cellular metabolic process } \\
(70.3 \% ; 2.142 e-22) \text {, and regulation of metabolic process } \\
(73.6 \% ; 1.740 e-21)\end{array}$ & 93 & 92 & $1.260 E-161$ \\
\hline
\end{tabular}


TABLE 2: qRT-PCR primer sequences and measurements for the potential curcumin-related genes analyzing by Affymetrix Chip.

\begin{tabular}{|c|c|c|c|c|c|}
\hline \multirow{2}{*}{ Unigene } & \multirow{2}{*}{ Symbol } & \multirow{2}{*}{ Forward primer } & \multirow{2}{*}{ Reverse primer } & \multicolumn{2}{|c|}{ Fold change } \\
\hline & & & & Affy. & Q-PCR \\
\hline Hs.116724 & AKR1B10 & TGGAAAAGCAACGTTCTTGGAT & TCTGGAAGTGGCTGAAATTGG & 14.19 & 6.623 \\
\hline Hs.159161 & ARHGDIA & GGATAAAAATCTCTTTCCGGGTTAA & CCTACCATGTAGTCAGTCTTGTCAATC & 5.771 & 0.96 \\
\hline Hs. 348350 & DHRS1 & CAAGATCCTAAGTGTGAACGTGAAGT & CAATGGAAGAGACCAGGATGACA & 0.486 & 0.093 \\
\hline Hs. 655387 & PIK3R3 & CAGACTGGAGGGAGGTGATGAT & TTGGAACTGCTGAAGTCATTGG & 0.437 & 0.601 \\
\hline Hs. 203717 & FN1 & GGAGTTGATTATACCATCACTG & TTTCTGTTTGATCTGGACCT & 0.375 & 0.248 \\
\hline Hs. 687708 & PTK2 & GCTTTGGCGGTTGCAATTAA & CACAATATGAGGATGGTCAAACTGA & 2.191 & 0.635 \\
\hline Hs.116237 & VAVl & TGTGAGAAGTTCGGCCTCAA & GGACAGAGCAGACAGGGTGTAGA & 0.402 & 0.904 \\
\hline Hs. 446336 & PXN & CTGGGCAGCAACCTTTCTG & GGGCTTGAGTTGGCCTCAT & 2.916 & 0.392 \\
\hline Hs.482077 & ITGA2 & GAAGTCTGTTGCCTGCGATGTA & GAGAGACGCCTGATTCTGAAGGT & 0.446 & 0.331 \\
\hline Hs. 390567 & FYN & CCTTGACAACTGGAGAGACAGGTT & TTTTCGGCCAAGTTTTCCAA & 0.488 & 0.255 \\
\hline Hs.531704 & PRKCA & CTGCGATCACTGTGGGTCACT & GGACATTGATGACGCATTGC & 0.494 & 0.497 \\
\hline Hs.433795 & SHC1 & AGAGTGGGCAGCCTAAGCATT & GTGGTAGCTGATAAGGTGACTGACA & 2.096 & 0.652 \\
\hline Hs.521482 & SHB & CAAGCTGCCCCAGGATGA & CGCTTCTCGTTGCCATTAAAC & 2.081 & 0.588 \\
\hline Hs. 159130 & RAF1 & TGTGGACAGCAGGATGATTGA & AGCCTGTTGGGCTCAGATTG & 2.543 & 0.704 \\
\hline Hs.471014 & TLN1 & GAAGCAGAAGGGAGAGCGTAAG & GAGAACGGGCTAGCTTCACGTA & 3.521 & 0.801 \\
\hline Hs.578508 & ADAM10 & ACTGTTCAGAACTATGGGTCTCATGT & TGTGCACTCTGTTCCAGAATCAT & 0.419 & 0.329 \\
\hline Hs.20516 & HDAC4 & GAGGTTGAGCGTGAGCAAGAT & GTAGCGGTGGAGGGACATGT & 0.245 & 0.167 \\
\hline Hs. 515487 & CALM1 & TGGGACAGAACCCCACTGAA & CAGGAACTCCGGGAAGTCAA & 2.475 & 0.399 \\
\hline Hs. 275775 & SEPP1 & GGACTCTTTTAAATGGAAGCAAAGA & AGGAAGGAAAAAGGCAAACCA & 0.242 & 0.215 \\
\hline Hs.523329 & ЕРНB2 & GGAGGGTGTCGTGACCAAGA & GACTGTGAACTGCCCATCGTTT & 0.469 & 0.296 \\
\hline
\end{tabular}

down-regulated by CUR in HCT-116 cells; results indicated that CD24 expression was significantly reduced by CUR in a dose-dependent manner (Figure 4(b)). This result suggests that CUR inhibited CD24 expression in CRC cells.

3.5. Curcumin Suppresses Sp-1 Transcriptional Activity and Its Downstream Gene Expressions. Further, we analyzed the underlying molecular mechanism of transcription genes associated with tumor cell migration, invasion, and metastasis. Sp-1 is mostly influenced by transcription factor that activates many genes containing GC box in their promoters involved in tumor progression. Our qRT-PCR results demonstrated that CUR suppresses the Sp-1 activation and its downstream genes including ADEM10, calmodulin, EPHB2, HDAC4, and SEPP1 in a concentration-dependent manner (Figure 5(a)). Cells treated with different concentrations of CUR suggested that expression of Sp-1 was not affected by CUR (Figure 5(b)). To directly clarify the possible role of CUR on Sp-1 activation, the HCT-116 cells were transiently transfected with PGL3-Sp-1 luciferase reporter plasmid which served as an indicator of Sp-1 activation, and then cells were treated with different concentrations of CUR for $24 \mathrm{~h}$. Results suggested that Sp-1 luciferase activity was inhibited by CUR in a concentration-dependent manner (Figure 5(c)). Our results indicate that CUR inhibits Sp-1 transcription factor and its downstream gene expressions which are involved in the metastasis. These data clearly suggest that CUR inhibits CRC metastasis through suppression of Sp-1 and its downstream gene expressions in CRC cell line.
3.6. Effect of Curcumin on FAK Regulated Cytoskeleton Remodeling and Cell Adhesion Pathways. We further analyzed antimetastasis effect of CUR on uncovered genes that contribute in tumor metastasis. MetaCore analysis showed that cytoskeleton remodeling, cell adhesion, and chemotaxis signaling pathways were associated with CUR mediated tumor metastasis (Figure 3(b)). Here, our result showed that CUR significantly suppressed FAK expression in a dose-dependent manner (Figure 6(a)) and also inhibited its phosphorylation (sites on Tyr397, 407, 576, 577, and 861) in HCT-116 cells (Figure 6(b)). FAK promotes cell invasion and adhesion through regulating focal adhesion turnover dynamics and cytoskeleton polymerization; we speculated that downregulation of FAK may be involved in cancer cell adhesion ability. After pretreatment with different concentrations of CUR for $24 \mathrm{~h}, \mathrm{HCT}-116$ cells were seeded on 96-well plates coated with different ECM, and then bound cells were stained by DAPI and analyzed by HCS. This result showed the enhancement of cell adhesion ability dose dependently after CUR treatment. We observed that CUR enhances cell adhesion ability through induction of ECM components collagen I, collagen III, collagen IV, collagen IX, laminin, and fibronectin in a concentration-dependent manner (Figure 6(c)). Taken together, these results suggested that CUR suppresses FAK activity via inhibition of its phosphorylation sites and also induces ECM components to enhance cell adhesion ability, thereby preventing detachment of tumor cells and cell migration. Inhibition of FAK expression leads to increased cell adhesion which might be potential mechanism of the antimetastasis effect of CUR. 


\begin{tabular}{lc}
\multicolumn{2}{c}{ Microarray probes } \\
\hline CD24 probe ID & Fold change \\
\hline 208650_s_at & 0.397 \\
208651x_at & 0.395 \\
216379_x_at & 0.308 \\
266_s_at & 0.276 \\
209772_s_at & 0.462 \\
209771_x_at & 0.308 \\
\hline
\end{tabular}

(a)

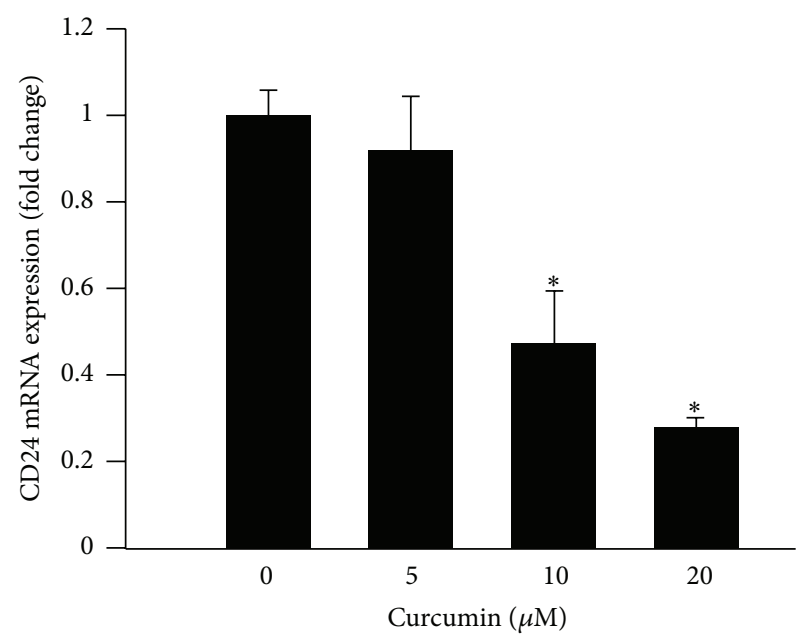

(b)

FIgure 4: Curcumin Inhibits CD24 expression in HCT-116 cells. (a) Gene expression fold change of CD24 was detected by Affymetrix microarray, indicating that CD24 was downregulated in 6 different probes. (b) Gene expression level of CD24 was validated by qRTPCR. Curcumin dose dependently inhibited the expression of CD24 mRNA which was consistent with microarray data. Data are presented as mean $\pm \mathrm{SD}(n=3) .{ }^{*} P<0.05$.

3.7. The Potential Inhibitory Effect of Curcumin on EpithelialMesenchymal Transition. EMT is a loss of epithelial cells morphology to acquire mesenchymal-like phenotype and plays a critical role in cancer progression and metastasis. On the other hand, to explore whether EMT was suppressed by CUR in CRC cell lines, we used two EMT markers, E-cad and thrombomodulin promoter, to examine the influence of CUR on EMT process. HCT-116 cells were transfected with E-cad promoter-GFP reporter plasmid or thrombomodulin promoter TM1519-GFP reporter plasmid. Stable cells were selected by using G418 treatment and fluorescenceactivated cell sorting (Figure 7(a)). The GFP positive cells were selected for the following CUR treatment. The images of the fluorescence intensity of each cell were analyzed by high content system (HCS) (Figure 7(b)). The results showed that CUR dose dependently increases both of the E-cad promoter (Figure 7(c)) and thrombomodulin promoter activity (Figure 7(d)). These data indicate that CUR prevents EMT through induction of E-cad and thrombomodulin expression in CRC cell line.

\section{Discussion}

Natural therapeutic drugs prevent tumor cell progression, invasion, and metastasis through modulation of growth factors, focal adhesive molecules, cell surface molecules, apoptosis-related genes, transcription factors, and signal transduction pathways. We already have reported that CUR induces apoptosis, causes downregulation of EGFR, Akt, cMET cyclin D1, and PCNA protein expression in CL-5 xenograft tumors [28], and inhibits lung cell invasion and metastasis through upregulation of HLJ1 expression in tumor cells [27]. CUR inhibits cell proliferation, cell cycle arrest and stimulates apoptosis via modulation of wide range of transcription factors, including NF- $\kappa$ B, AP-1, Erg-1, STAT-3, p53, $\beta$-catenin, Notch-1, Hif-1, and PPAR- $\alpha$ [30]. However, the molecular mechanism of CUR on Sp-1, focal adhesion molecules, and cell-cell adhesion component has not been implicated. Very little information is available regarding the effect of CUR on Sp-1 in CRC cells. Several studies have reported that $\mathrm{Sp}-1$ is responsible for upregulation of housekeeping genes (VEGF, uPA, uPAR, and EGFR) which participate in tumor cell angiogenesis and metastasis [57]. Hence, inhibition of Sp-1 and its housekeeping gene expressions is an important hypothesis to prevents tumor formation, migration, and invasion [31,32]. Our microarray, qRT-PCR, and luciferase assay data showed that CUR suppresses the $\mathrm{Sp}-1$ activation and its downstream genes including ADEM10, calmodulin, EPHB2, HDAC4, and SEPP1 in a concentration-dependent manner in CRC cell lines; these results are consistent with other studies where it has been reported that CUR suppresses the Sp-1 activity in bladder cancer [33] and decreases DNA binding activity of Sp-1 in NSCLC cells [34]. Our data raise the possibility that CUR may prevent metastasis ability of CRC cells in vitro and in vivo through inhibition of Sp-1 and its housekeeping gene expressions which are known to be involved in tumor progression. Moreover, the CUR significantly reduced colony formation; results are in agreement with other studies demonstrating that downregulation of $\mathrm{Sp}-1$ prevents the colony formation in a patient derived fibrocarcinoma cell line [35]. Our results suggest that downregulation of Sp1 and its downstream genes leads to inhibition of colony formation, and transactivation gene expression might be a possible mechanism for preventing the colorectal tumor cell metastasis, because the Sp-1 serves as a master switch to turn on and off the housekeeping gene expressions which play vital roles in tumorigenesis [35].

4.1. Potential Role of FAK Signaling in the Antimetastasis Effect of Curcumin. Studies have implicated that FAK mediates cell proliferation through upregulation of cyclin D3, PKC, and PI3K/Akt signaling pathways [36] and by interacting with Src, Grb, PI3K, and P130CAS which promotes cell migration [9]. Loss of FAK activity is associated with suppression of tumor formation [37], reduced cell attachment with ECM, and reduced cell adhesion to collagen type II [38]. These studies implicated that FAK expression is related to tumor cell migration. It is well known that FAK phosphorylation sites (Tyr397, 407, 576, 577 861, and 925) are involved in multiple 




(a)

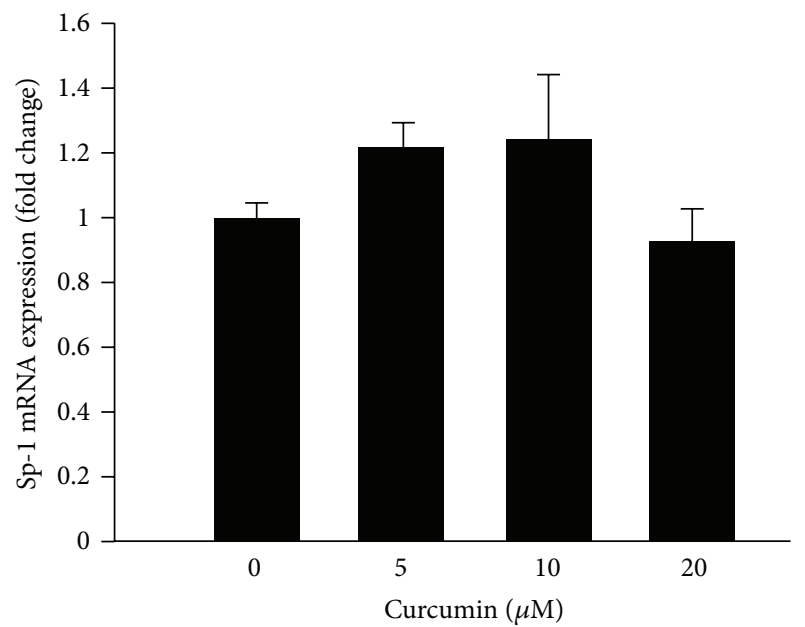

(b)

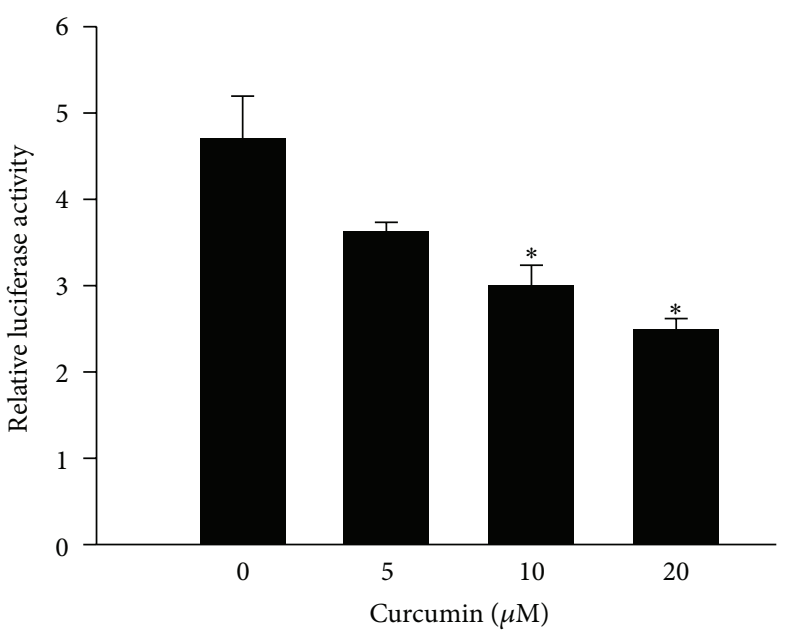

(c)

FIGURE 5: Sp-1 transcriptional regulation via curcumin treatment. (a) Gene expression fold changes of five Sp-1 downstream genes, containing ADAM10, calmodulin, EPHB2, HDAC4, and SEPP1, were determined using qRT-PCR. Five genes transcriptionally activated by Sp-1 showed uniformly suppression via curcumin treatment. (b) The gene expression level of Sp-1 was measured by qRT-PCR. (c) Luciferase reporter assay quantifying the Sp-1 transcriptional activity changes in curcumin treated cells. HEK293T cells transiently transfected with Sp-1 reporter plasmid and Renilla control plasmid were treated with different concentrations of curcumin. The firefly and Renilla luciferase activities of the cell extracts were quantified using the Dual-Glo luciferase assay system. Data are presented as the ratio of firefly:Renilla luciferase activity. ${ }^{*} P<0.05$.

biological activities including phosphorylation of Tyr397 to promote cell motility and cell migration, Tyr576 and Tyr577 to increase catalytic activity, and Tyr925 to bind with $\mathrm{SH} 2$ domain of Grb2 and also to activate Ras signaling pathways $[16,39,40]$. In this study, we further investigated CUR effect on FAK in CRC tumor cell lines. We found that CUR suppresses FAK phosphorylation sites at Tyr397, 407, 576, 577, 861, and 925 in HCT-116 cells; result is partly consistent with other studies where it has been reported that CUR inhibits cell growth and migration through FAK activities [41]. CUR abrogates the chondrogenesis by downregulation of integrins and FAK leading to cytoskeleton remodeling by Akt signals [42]. CUR prevents mouse-rat hybrid retina ganglion cell migration and invasion via abrogation of FAK MMP-2, MMP-9, Rho-A, and ROCK gene expressions [29]. Cellular adhesion molecules and proteolysis activities determine the fate of tumor cell interactions with extra cellular matrix (ECM) and whether it leads to a path for tumor cell migration and angiogenesis. We also observed that CUR enhances cell adhesion ability through induction of ECM components collagens I, III, IV, and IX, laminin, and fibronectin in a concentration-dependent manner. These results suggest that CUR induces ECM components to enhance cell adhesion ability thereby preventing detachment of tumor cells. Inhibition of FAK expression leads to increase of the cell adhesion and prevention of cell migration which might be potential mechanism of antimetastasis effect of CUR. Our results suggest that CUR prevents colorectal cell progression and migration through inhibition of FAK, because downstream of FAK associates with reduced cell migration; for example, 


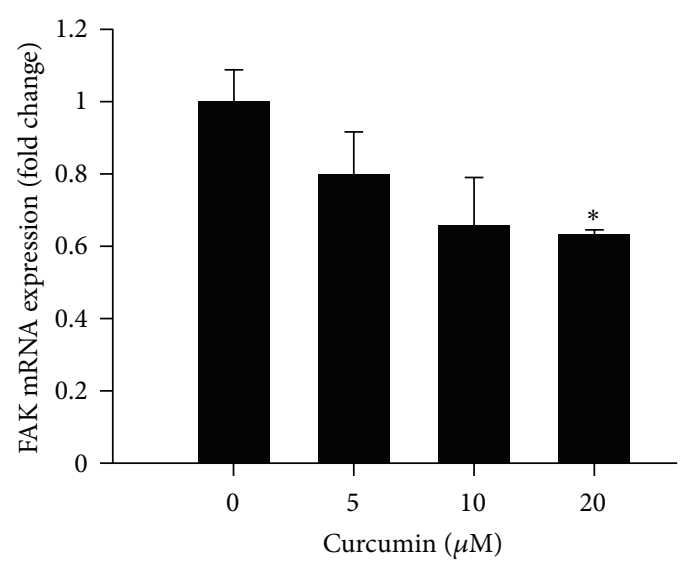

(a)



(b)

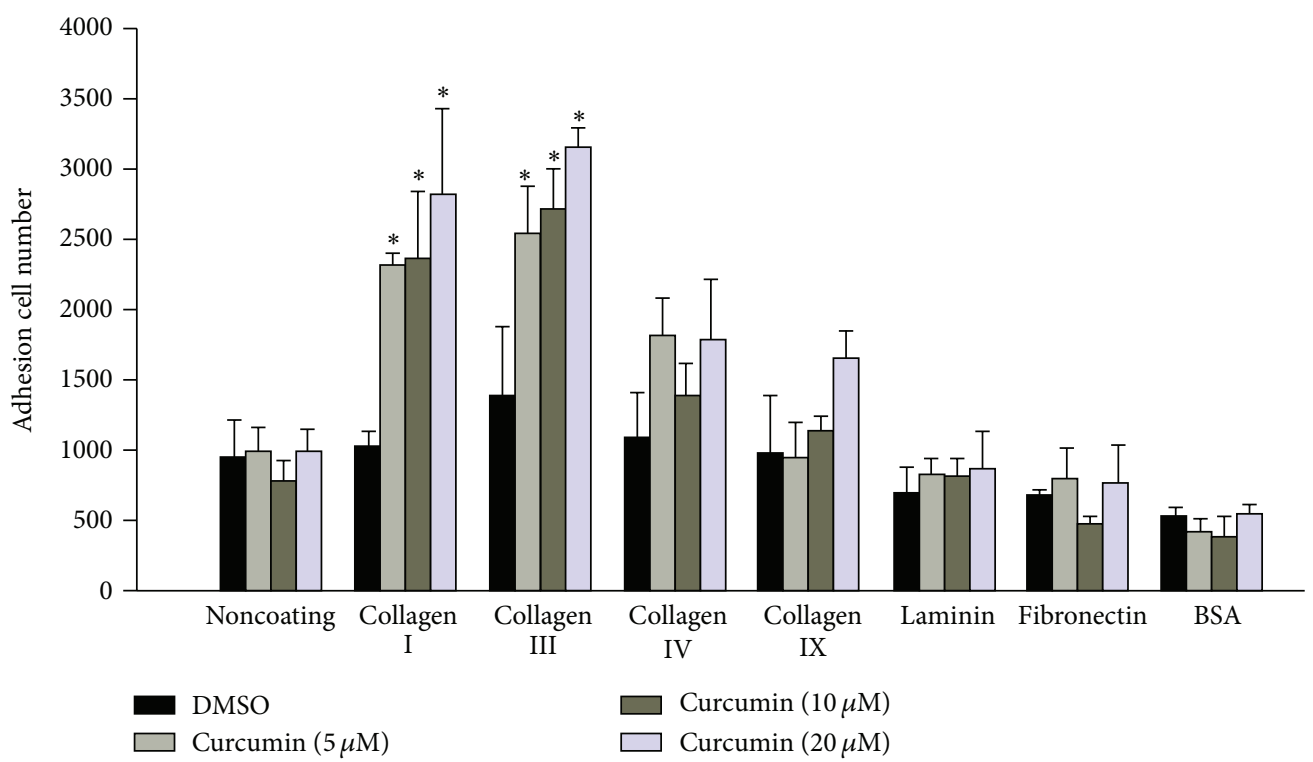

(c)

FIgURE 6: The effect of curcumin on FAK expression and cell adhesion. (a) FAK mRNA levels were suppressed under curcumin treatment and detected by qRT-PCR. (b) Curcumin inhibits the protein expression and phosphorylation of FAK. HCT-116 cells were treated with different concentrations of curcumin for $24 \mathrm{~h}$. The cell lysates were harvested and analyzed by specific antibodies against FAK and different tyrosine phosphorylation sites of FAK, including 397, 407, 576, 577, and 861. (c) Curcumin enhances cell adhesion ability. After pretreatment with serial curcumin for $24 \mathrm{~h}, 2 \times 10^{4}$ cells were seeded on 96-well plates coated with different ECM, including collagen I, collagen III, collagen IV, collagen IX, laminin, and BSA as negative control. The noncoating control at the first lane was performed to control added cell number. Cells were allowed to adhere for $1 \mathrm{~h}$ at $37^{\circ} \mathrm{C}$ and then washed twice with PBS. Bound cells were stained by DAPI and analyzed by high content system. Data are presented as mean $\pm \mathrm{SD}(n=3) .{ }^{*} P<0.05$.

FAK deficient fibroblast shows an increased focal contact formation in culture cells [43] and reduces cell migration in glioblastoma cell lines [44]. Based on our present data, we suggest that CUR prevents CRC cell migration and invasion via inhibition of FAK activation, while enhancing ECM components to increase cell adhesion ability in CRC cell lines.

4.2. Curcumin Downregulates CD24 in CRC. The precise molecular mechanism of CUR on cell surface molecule CD24 has not been investigated in CRC cells. CD24 is a cell surface molecule that is employed as a gate keeper to lipid rafts within cell membrane and also promotes FAK and paxillin expression, motility, and invasion in a Src-dependent manner [17]. It was reported that CD44 is associated with FAK, paxillin, and Src activity, and the loss of CD24 expression significantly decreases cell proliferation, cell invasion, and metastasis nodules of CRC and pancreatic cancer in mice model [45]. There is possibility that inhibition of CD24 might reduce CRC cell proliferation, cell invasion, and metastasis nodules of CRC and pancreatic cancer in mice model [45]. As anticipated, our microarray analysis and qRT-PCR data indicate that CUR suppresses CD24 mRNA expression in HCT-116 cells. To our knowledge, this is the first report demonstrating that CUR has shown inhibitory effect on CD24 expression in CRC cell lines. Moreover, the CUR 

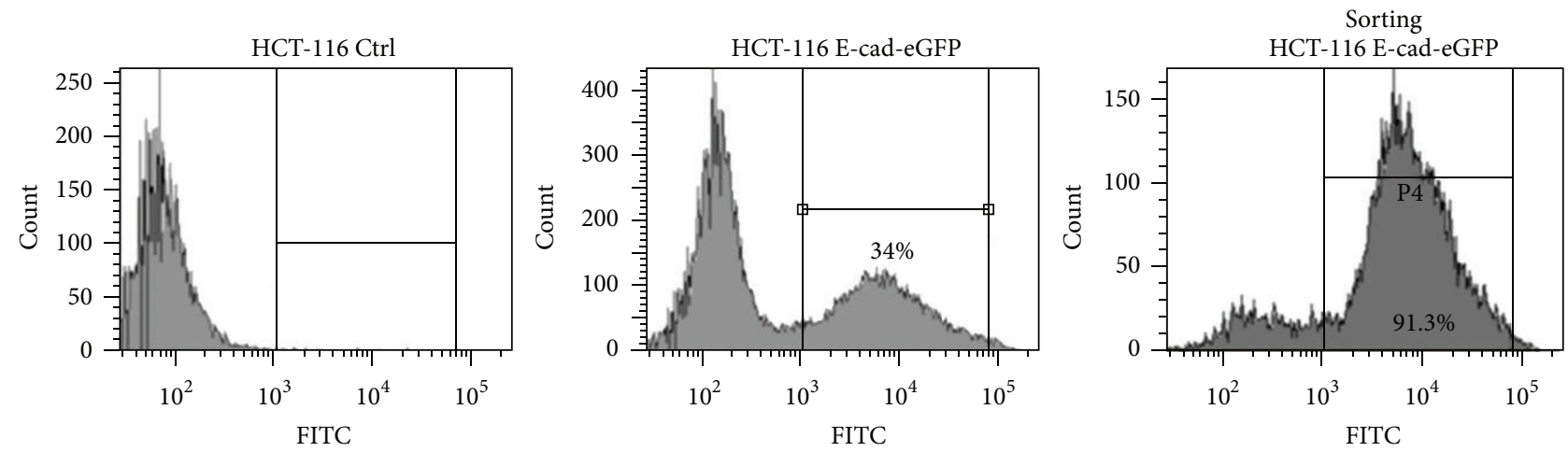

(a)
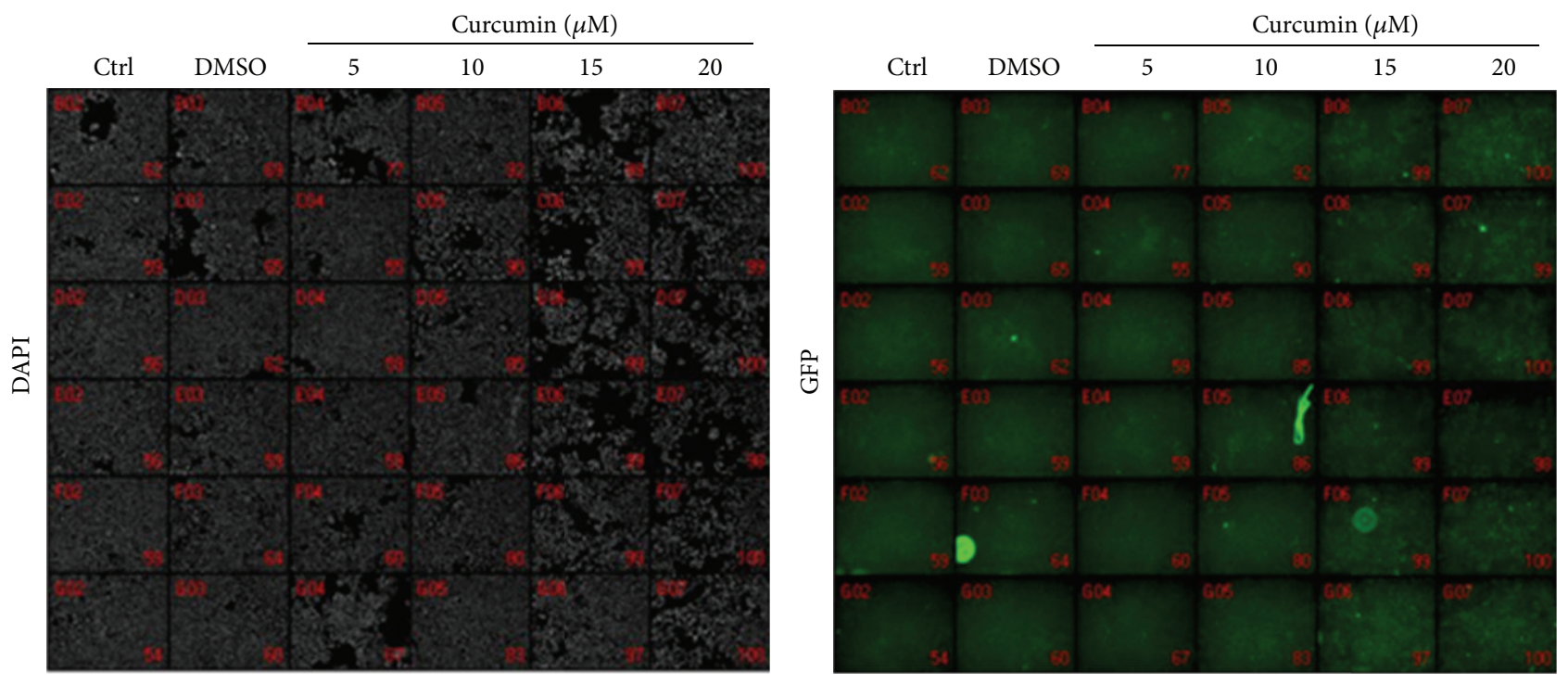

(b)

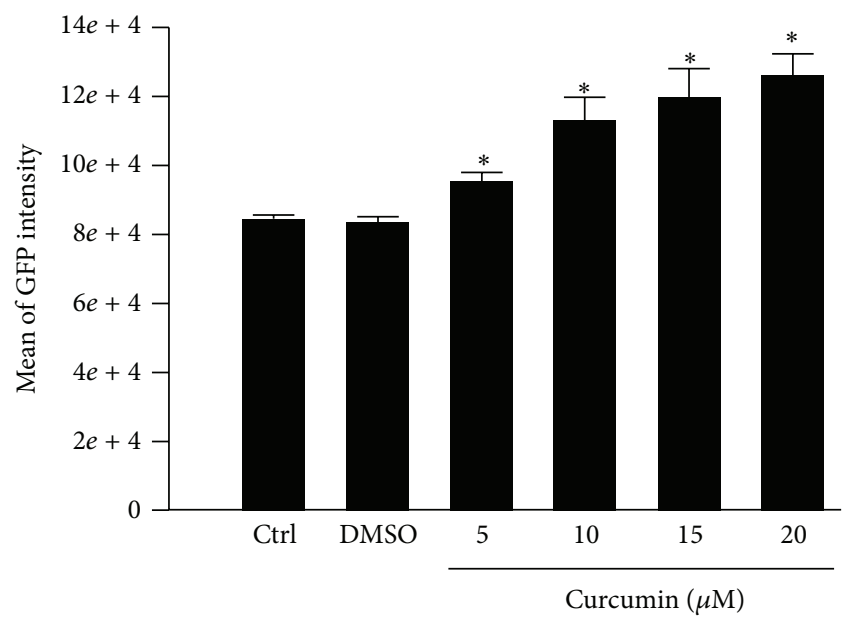

(c)

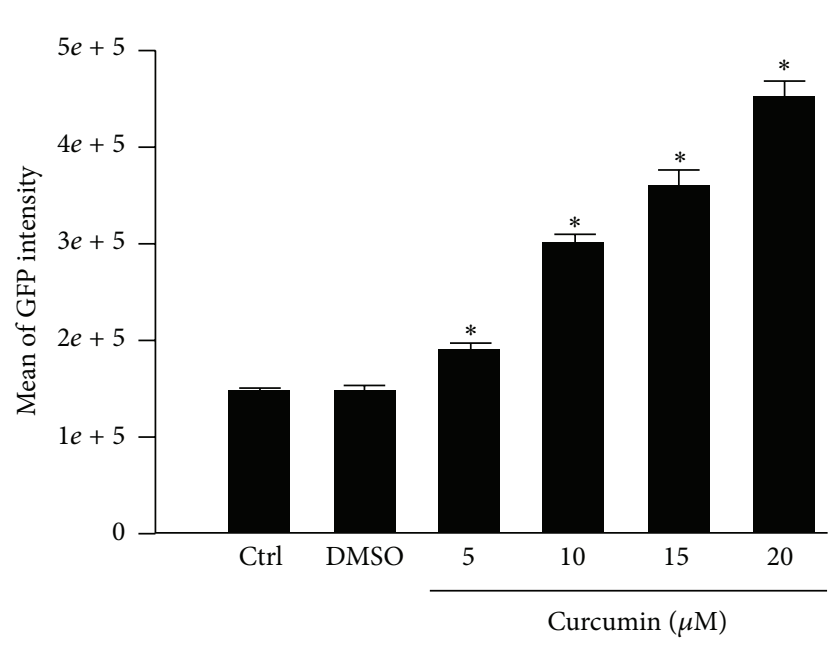

(d)

FIGURE 7: The potential inhibitory effect of curcumin on epithelial-mesenchymal transition. (a) The percentage of GFP positive cells was increased from $34 \%$ to $91.3 \%$ after fluorescence-activated cell sorting. (b) Curcumin increases GFP intensity of the selected HCT-116 stable cells. $1 \times 10^{4}$ cells were seeded in 96-well plates overnight. After incubation with different doses of curcumin for $24 \mathrm{~h}$, the cells were fixed and stained with DAPI. The images of 96-well plates were acquired, and the fluorescence intensity of each cell was analyzed by HCS. (c) Curcumin increases E-cadherin promoter activity in dose-dependent manner. (d) Curcumin increases thrombomodulin promoter activity in dose-dependent manner. Data are presented as mean $\pm \mathrm{SD}(n=3) .{ }^{*} P<0.05$. 
prevents CRC cell proliferation and metastasis through attenuation of CD24, Sp-1, and FAK activities in CRC cells, because the CD11b and CD24 associated with Sp-1 lead to promoter activity and regulation of progression of sclerosis $[13,46]$. The CD24 mediates c-Src kinase for FAK phosphorylation and paxillin which in turn promote integrin-dependent adhesion and tumor cell invasion and metastasis [17]. Our results clearly implicate that CUR prevents CRC cell metastasis via inhibition of CD24 interaction with Sp-1 and FAK in CRC tumor cells.

4.3. Curcumin Enhances E-Cadherin Expression in CRC Cells. Cadherins regulate cytoskeleton remodeling and adhesion junctions through interaction with $\beta$-catenin and stabilize adhesive contact and polarization of epithelial cells. The $\beta$-catenin disassociates from E-cad and then translocated into nucleus from cytoplasm, where it is engaged with other transcription factors of $\beta$-catenin/TCF/Lef-dependent transactivation genes $[22,47]$. Loss of cell-cell adhesion of tumor cells leads to invasion and metastasis into surrounding tissues [21]. It was reported that CUR could activate protein kinase D1 (PKD1) suggesting that suppressing of $\beta$-catenin transcriptional activity prevents growth of prostate cancer [48]. We have already reported that CUR stimulates DnaJlike heat shock protein via activation of c-Jun $\mathrm{NH}(2)$-kinase (JNK/JunD) signaling pathway and by causing upregulation of E-cad to suppress lung cancer cell invasion [27]. In this study, CUR induced E-cad expression in HCT-116 cells; results are in agreement with other studies where it was indicated that CUR attenuates nasopharyngeal carcinoma cells migration through inhibition of $\mathrm{NF}-\kappa \mathrm{B}$ and by inducing the E-cad expression [49]. These results suggest that loss of E-cad adhesion leads to disruption of cell-cell adhesion and dissemination of tumor cells from epithelial cell to surrounding tissue. Therefore, CUR induced increases in E-cad expression on membrane promote the cell-cell tight junctions or intact cell-cell contacts and prevent EMT which is known to lead to inhibition of CRC cell migration, invasion, and metastasis.

4.4. Potential Role of EMT in Antimetastasis Effect of Curcumin. It is well known that loss of adhesion contacts in epithelial cells leads to acquired mesenchymal-like phenotype that plays central role in cancer cells invasion [50]. It was reported that EMT-related genes modulate hepatocellular carcinoma cells through CD133 expression. We have already reported that CUR induces E-cad expression through the tumor suppressor HLJ1 in lung tumor cells [27]. In this study, we found that CUR enhances the promoter activity of E-cad and thrombomodulin suggesting that an increased E-cad expression might stabilize the CRC cell-cell contact that prevents tumor cell migration. CUR suppresses the LPS induced EMT via inhibition of NF- $\kappa \mathrm{B}$, snail activity, and enhanced E-cad expression in breast cancer cells [51]. It was reported that $\mathrm{Sp}-1$ mediates the transforming growth factor- $\beta$ (TNF- $\beta$ ) stimulated EMT and cell migration [52], and also downregulates E-cad and upregulation of MMP9, thereby loss of cell-cell contact resulting in EMT, which in turn results in tumor cell invasion and metastasis. In this study, CUR inhibited CRC tumor cell metastasis via inhibition of transcription factor Sp-1 and its downstream gene expressions, while preventing cell migration through inhibition of FAK activation, CD24 expression and through increasing the ECM components and E-cad expression for enhanced cell adhesion ability in CRC cells. Suppression of transcription factor and focal adhesion molecule activities and increase in cell-cell adhesion molecule may inhibit the CRC cell metastasis. Inhibition of Sp-1 and promotion of Ecad expression may be an effective strategy for successful treatment of CUR to resistance of CRC metastasis.

4.5. Conclusion. Our data demonstrates the underlying molecular mechanism of CUR on CRC cell metastasis both in vivo and in vitro models. CUR is potentially inhibited by CRC cell metastasis through downregulation of $\mathrm{Sp}-1$ transcription factor and its downstream signals, also prevents CRC cell invasion through suppression of FAK activation, while enhancing cell adhesion ability by increase of ECM components and promotion of E-cad expression in CRC cells. CUR is a potential novel therapeutic drug for the treatment of metastatic disease, because CUR abrogates CRC cell metastasis at different levels, particularly inhibition of transcription factor, cell adhesion molecules, and cell surface marker and enhances cell adhesion ability and cell-cell tight junctions to prevent EMT.

\section{Conflict of Interests}

The authors declare that there is no conflict of interests.

\section{Authors Contribution}

Chun-Chieh Chen and Munisamy Sureshbabu contributed equally to this work.

\section{Acknowledgments}

This study was supported by the National Science Council of China (Grants NSC98-2314-B-002-120-MY3, NSC98-2314-B002-022-MY3, NSC102-2911-I-002-303, and 102R7557). The authors also thank the NCFPB C5 microarray core facility for technique support.

\section{References}

[1] R. Siegel, D. Naishadham, and A. Jemal, "Cancer statistics, 2012," CA Cancer Journal for Clinicians, vol. 62, no. 1, pp. 10-29, 2012.

[2] C.-J. Chiang, Y.-C. Chen, C.-J. Chen, S.-L. You, and M.-S. Lai, "Cancer trends in Taiwan," Japanese Journal of Clinical Oncology, vol. 40, no. 10, pp. 897-904, 2010.

[3] M. A. Pourhoseingholi, "Increased burden of colorectal cancer in Asia," The World Journal of Gastrointestinal Oncology, vol. 4, pp. 68-70, 2012.

[4] M. F. Leber and T. Efferth, "Molecular principles of cancer invasion and metastasis," International Journal of Oncology, vol. 34, no. 4, pp. 881-895, 2009.

[5] Q. Shi, X. Le, J. L. Abbruzzese et al., "Constitutive Spl activity is essential for differential constitutive expression of vascular 
endothelial growth factor in human pancreatic adenocarcinoma," Cancer Research, vol. 61, no. 10, pp. 4143-4154, 2001.

[6] A. Zannetti, S. Del Vecchio, M. V. Carriero et al., "Coordinate up-regulation of Spl DNA-binding activity and urokinase receptor expression in breast carcinoma," Cancer Research, vol. 60, no. 6, pp. 1546-1551, 2000.

[7] Y. Kitadai, W. Yasui, H. Yokozaki et al., "The level of a transcription factor Sp1 is correlated with the expression of EGF receptor in human gastric carcinomas," Biochemical and Biophysical Research Communications, vol. 189, no. 3, pp. 1342-1348, 1992.

[8] D. D. Schlaepfer, C. R. Hauck, and D. J. Sieg, "Signaling through focal adhesion kinase," Progress in Biophysics and Molecular Biology, vol. 71, no. 3-4, pp. 435-478, 1999.

[9] T.-L. Shen and J.-L. Guan, "Differential regulation of cell migration and cell cycle progression by FAK complexes with Src, PI3K, Grb7 and Grb2 in focal contacts," The FEBS Letters, vol. 499, no. 1-2, pp. 176-181, 2001.

[10] Q. Yu and I. Stamenkovic, "Cell surface-localized matrix metaloproteinase- 9 proteolytically activates TGF- $\beta$ and promotes tumor invasion and angiogenesis," Genes and Development, vol. 14, no. 2, pp. 163-176, 2000.

[11] F. van Roy and G. Berx, "The cell-cell adhesion molecule Ecadherin," Cellular and Molecular Life Sciences, vol. 65, no. 23, pp. 3756-3788, 2008.

[12] J. R. Davie, S. He, L. Li et al., "Nuclear organization and chromatin dynamics-Sp1, Sp3 and histone deacetylases," Advances in Enzyme Regulation, vol. 48, no. 1, pp. 189-208, 2008.

[13] H.-M. Chen, H. L. Pahl, R. J. Scheibe, D.-E. Zhang, and D. G. Tenen, "The Sp1 transcription factor binds the CD1lb promoter specifically in myeloid cells in vivo and is essential for myeloidspecific promoter activity," Journal of Biological Chemistry, vol. 268, no. 11, pp. 8230-8239, 1993.

[14] X. Wang, A. M. Urvalek, J. Liu, and J. Zhao, "Activation of KLF8 transcription by focal adhesion kinase in human ovarian epithelial and cancer cells," Journal of Biological Chemistry, vol. 283, no. 20, pp. 13934-13942, 2008.

[15] J. S. Waby, H. Chirakkal, C. Yu et al., "Sp1 acetylation is associated with loss of DNA binding at promoters associated with cell cycle arrest and cell death in a colon cell line," Molecular Cancer, vol. 9, article 275, 2010.

[16] B. D. Cox, M. Natarajan, M. R. Stettner, and C. L. Gladson, "New concepts regarding focal adhesion kinase promotion of cell migration and proliferation," Journal of Cellular Biochemistry, vol. 99, no. 1, pp. 36-52, 2006.

[17] P. Baumann, W. Thiele, N. Cremers et al., "CD24 interacts with and promotes the activity of c-src within lipid rafts in breast cancer cells, thereby increasing integrin-dependent adhesion," Cellular and Molecular Life Sciences, vol. 69, no. 3, pp. 435-448, 2012.

[18] G. Christofori, "New signals from the invasive front," Nature, vol. 441, no. 7092, pp. 444-450, 2006.

[19] N. P. Bretz, A. V. Salnikov, C. Perne et al., "CD24 controls Src/STAT3 activity in human tumors," Cellular and Molecular Life Sciences, vol. 69, pp. 3863-3879, 2012.

[20] P. Ye, M. A. Nadkarni, and N. Hunter, "Regulation of E-cadherin and TGF- $\beta 3$ expression by CD24 in cultured oral epithelial cells," Biochemical and Biophysical Research Communications, vol. 349, no. 1, pp. 229-235, 2006.

[21] X. Chen, Y. Wang, H. Xia et al., "Loss of E-cadherin promotes the growth, invasion and drug resistance of colorectal cancer cells and is associated with liver metastasis," Molecular Biology Reports, vol. 39, pp. 6707-6714, 2012.
[22] S. Orsulic, O. Huber, H. Aberle, S. Arnold, and R. Kemler, "Ecadherin binding prevents $\beta$-catenin nuclear localization and $\beta$-catenin/LEF-1-mediated transactivation," Journal of Cell Science, vol. 112, no. 8, pp. 1237-1245, 1999.

[23] S. C. Gupta, S. Prasad, J. H. Kim et al., "Multitargeting by curcumin as revealed by molecular interaction studies," Natural Product Reports, vol. 28, no. 12, pp. 1937-1955, 2011.

[24] R. Kuttan, P. Bhanumathy, K. Nirmala, and M. C. George, "Potential anticancer activity of turmeric (Curcuma longa)," Cancer Letters, vol. 29, no. 2, pp. 197-202, 1985.

[25] A. J. Ruby, G. Kuttan, K. Dinesh Babu, K. N. Rajasekharan, and R. Kuttan, "Anti-tumour and antioxidant activity of natural curcuminoids," Cancer Letters, vol. 94, no. 1, pp. 79-83, 1995.

[26] H. Chen, Z.-S. Zhang, Y.-L. Zhang, and D.-Y. Zhou, "Curcumin inhibits cell proliferation by interfering with the cell cycle and inducing apoptosis in colon carcinoma cells," Anticancer Research, vol. 19, no. 5, pp. 3675-3680, 1999.

[27] H.-W. Chen, J.-Y. Lee, J.-Y. Huang et al., "Curcumin inhibits lung cancer cell invasion and metastasis through the tumor suppressor HLJ1," Cancer Research, vol. 68, no. 18, pp. 7428$7438,2008$.

[28] J.-Y. Lee, Y.-M. Lee, G.-C. Chang et al., "Curcumin induces EGFR degradation in lung adenocarcinoma and modulates p38 activation in intestine: the versatile adjuvant for gefitinib therapy," PLoS ONE, vol. 6, no. 8, Article ID e23756, 2011.

[29] H.-J. Lin, C.-C. Su, H.-F. Lu et al., "Curcumin blocks migration and invasion of mouse-rat hybrid retina ganglion cells (N18) through the inhibition of MMP-2, -9, FAK, Rho a and Rock-1 gene expression," Oncology Reports, vol. 23, no. 3, pp. 665-670, 2010.

[30] S. Shishodia, T. Singh, and M. M. Chaturvedi, "Modulation of transcription factors by curcumin," Advances in Experimental Medicine and Biology, vol. 595, pp. 127-148, 2007.

[31] J. H. Leupold, H.-S. Yang, N. H. Colburn, I. Asangani, S. Post, and H. Allgayer, "Tumor suppressor Pdcd4 inhibits invasion/intravasation and regulates urokinase receptor (u-PAR) gene expression via Sp-transcription factors,' Oncogene, vol. 26, no. 31, pp. 4550-4562, 2007.

[32] S.-G. Cho, Z. Yi, X. Pang et al., "Kisspeptin-10, a KISS1-derived decapeptide, inhibits tumor angiogenesis by suppressing Sp1mediated VEGF expression and FAK/Rho GTPase activation," Cancer Research, vol. 69, no. 17, pp. 7062-7070, 2009.

[33] G. Chadalapaka, I. Jutooru, S. Chintharlapalli et al., "Curcumin decreases specificity protein expression in bladder cancer cells," Cancer Research, vol. 68, no. 13, pp. 5345-5354, 2008.

[34] S. Aigner, C. L. Ramos, A. Hafezi-Moghadam et al., "CD24 mediates rolling of breast carcinoma cellson P-selectin," The FASEB Journal, vol. 12, no. 12, pp. 1241-1251, 1998.

[35] Z. Lou, S. O’Reilly, H. Liang, V. M. Maher, S. D. Sleight, and J. J. McCormick, "Down-regulation of overexpression Spl protein in human fibrosarcoma cell lines inhibits tumor formation," Cancer Research, vol. 65, no. 3, pp. 1007-1017, 2005.

[36] D. Yamamoto, Y. Sonoda, M. Hasegawa, M. Funakoshi-Tago, E. Aizu-Yokota, and T. Kasahara, "FAK overexpression upregulates cyclin D3 and enhances cell proliferation via the PKC and PI3-kinase-Akt pathways," Cellular Signalling, vol. 15, no. 6, pp. 575-583, 2003.

[37] G. W. McLean, N. H. Komiyama, B. Serrels et al., "Specific deletion of focal adhesion kinase suppresses tumor formation and blocks malignant progression," Genes and Development, vol. 18, no. 24, pp. 2998-3003, 2004. 
[38] J. W. Lee, Y. H. Kim, H. B. Park et al., “The C-terminal domain of focal adhesion kinase reduces the tumor cell invasiveness in chondrosarcoma cell lines," Journal of Orthopaedic Research, vol. 21, no. 6, pp. 1071-1080, 2003.

[39] M. B. Calalb, T. R. Polte, and S. K. Hanks, "Tyrosine phosphorylation of focal adhesion kinase at sites in the catalytic domain regulates kinase activity: a role for Src family kinases," Molecular and Cellular Biology, vol. 15, no. 2, pp. 954-963, 1995.

[40] D. D. Schlaepfer and T. Hunter, "Evidence for in vivo phosphorylation of the Grb2 SH2-domain binding site on focal adhesion kinase by Src-family protein-tyrosine kinases," Molecular and Cellular Biology, vol. 16, pp. 5623-5633, 1996.

[41] T.-H. Leu, S. L. Su, Y.-C. Chuang, and M.-C. Maa, "Direct inhibitory effect of curcumin on Src and focal adhesion kinase activity," Biochemical Pharmacology, vol. 66, no. 12, pp. 23232331, 2003.

[42] D. Kim, S.-J. Kim, S.-S. Kang, and E.-J. Jin, "Curcumin inhibits cellular condensation and alters microfilament organization during chondrogenic differentiation of limb bud mesenchymal cells," Experimental and Molecular Medicine, vol. 41, no. 9, pp. 656-664, 2009.

[43] D. Ilic, Y. Furuta, T. Suda et al., "Focal adhesion kinase is not essential for in vitro and in vivo differentiation of ES cells," Biochemical and Biophysical Research Communications, vol. 209, no. 1, pp. 300-309, 1995.

[44] M. Tamura, J. Gu, T. Takino, and K. M. Yamada, “Tumor suppressor PTEN inhibition of cell invasion, migration, and growth: differential involvement of focal adhesion kinase and p130(Cas)," Cancer Research, vol. 59, no. 2, pp. 442-449, 1999.

[45] P. K. Sood, U. Nahar, and B. Nehru, "Curcumin attenuates aluminum-induced oxidative stress and mitochondrial dysfunction in rat brain," Neurotoxicity Research, vol. 20, no. 4, pp. 351-361, 2011.

[46] L. Wang, R. Liu, D. Li et al., "A hypermorphic SP1-binding CD24 variant associates with risk and progression of multiple sclerosis," American Journal of Translational Research, vol. 4, pp. 347-356, 2012.

[47] V. A. Torres, J. C. Tapia, D. A. Rodriguez et al., "E-cadherin is required for caveolin-1-mediated down-regulation of the inhibitor of apoptosis protein survivin via reduced $\beta$-cateninTcf/Lef- dependent transcription," Molecular and Cellular Biology, vol. 27, no. 21, pp. 7703-7717, 2007.

[48] V. Sundram, S. C. Chauhan, M. Ebeling, and M. Jaggi, "Curcumin attenuates $\beta$-catenin signaling in prostate cancer cells through activation of protein kinase D1," PLoS ONE, vol. 7, no. 4, Article ID e35368, 2012.

[49] T.-S. Wong, W.-S. Chan, C.-H. Li et al., "Curcumin alters the migratory phenotype of nasopharyngeal carcinoma cells through up-regulation of E-cadherin," Anticancer Research, vol. 30, no. 7, pp. 2851-2856, 2010.

[50] J. M. Lee, S. Dedhar, R. Kalluri, and E. W. Thompson, "The epithelial-mesenchymal transition: new insights in signaling, development, and disease," Journal of Cell Biology, vol. 172, no. 7, pp. 973-981, 2006.

[51] T. Huang, Z. Chen, and L. Fang, "Curcumin inhibits LPSinduced EMT through downregulation of NF-kappaB-Snail signaling in breast cancer cells," Oncology Reports, vol. 29, pp. 117-124, 2013.

[52] K. Jungert, A. Buck, G. von Wichert et al., "Spl is required for transforming growth factor- $\beta$-induced mesenchymal transition and migration in pancreatic cancer cells," Cancer Research, vol. 67, no. 4, pp. 1563-1570, 2007. 


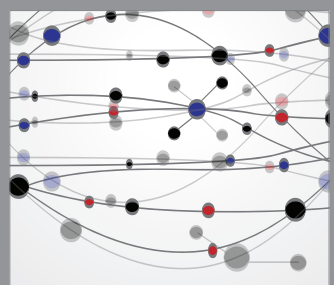

The Scientific World Journal
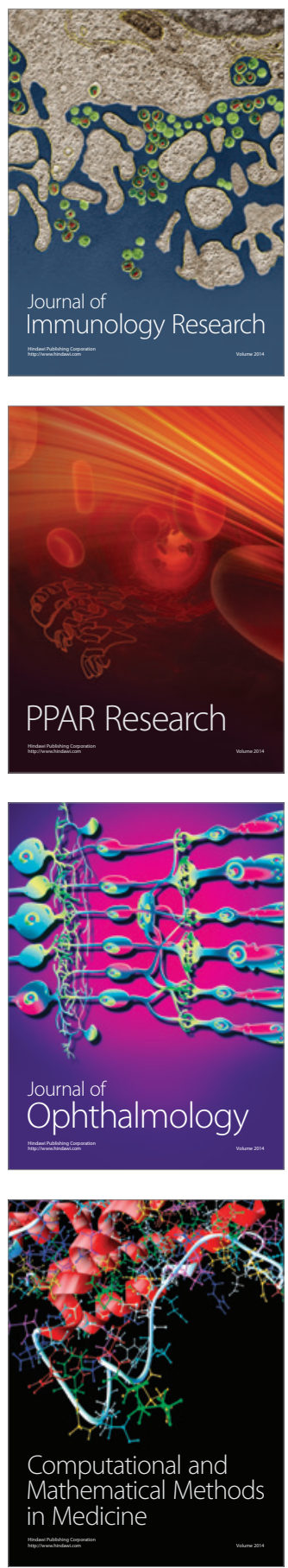

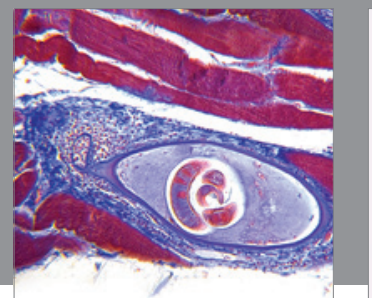

Gastroenterology

Research and Practice
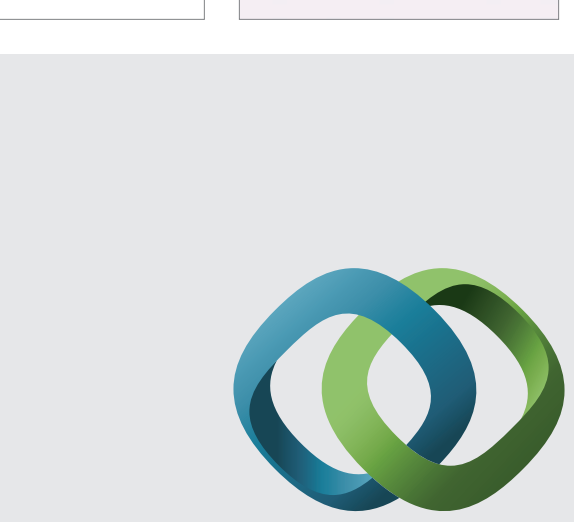

\section{Hindawi}

Submit your manuscripts at

http://www.hindawi.com
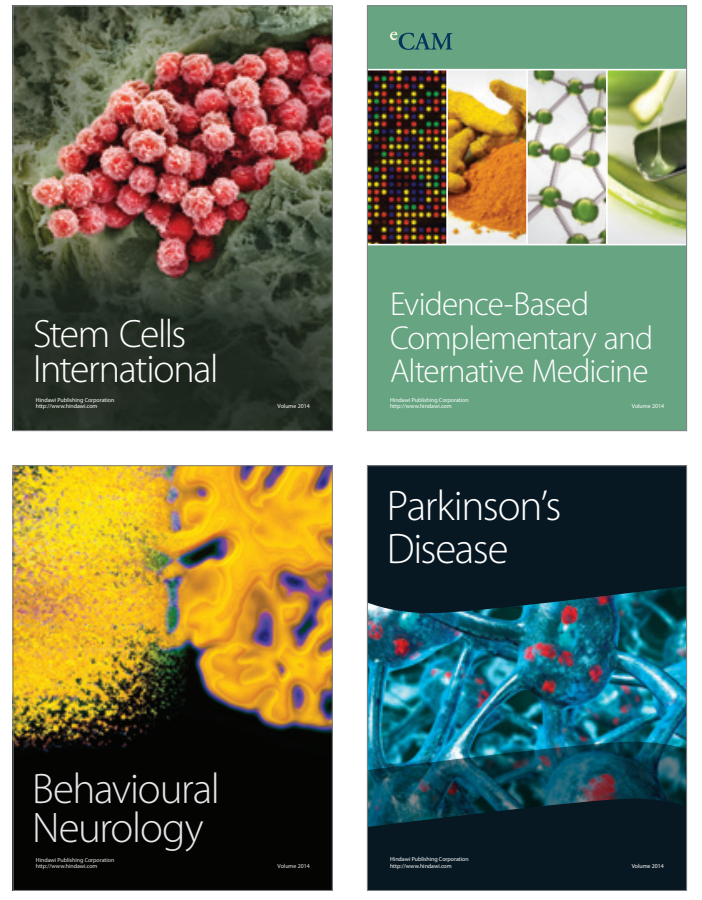
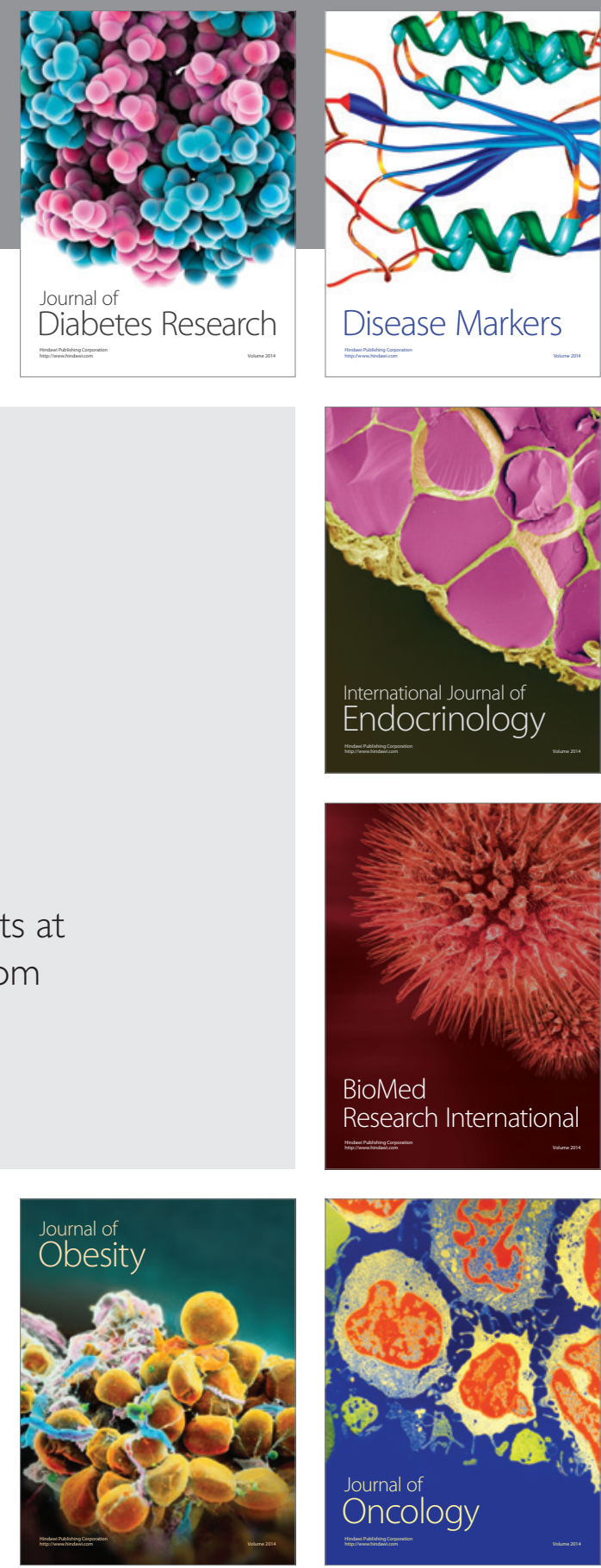

Disease Markers
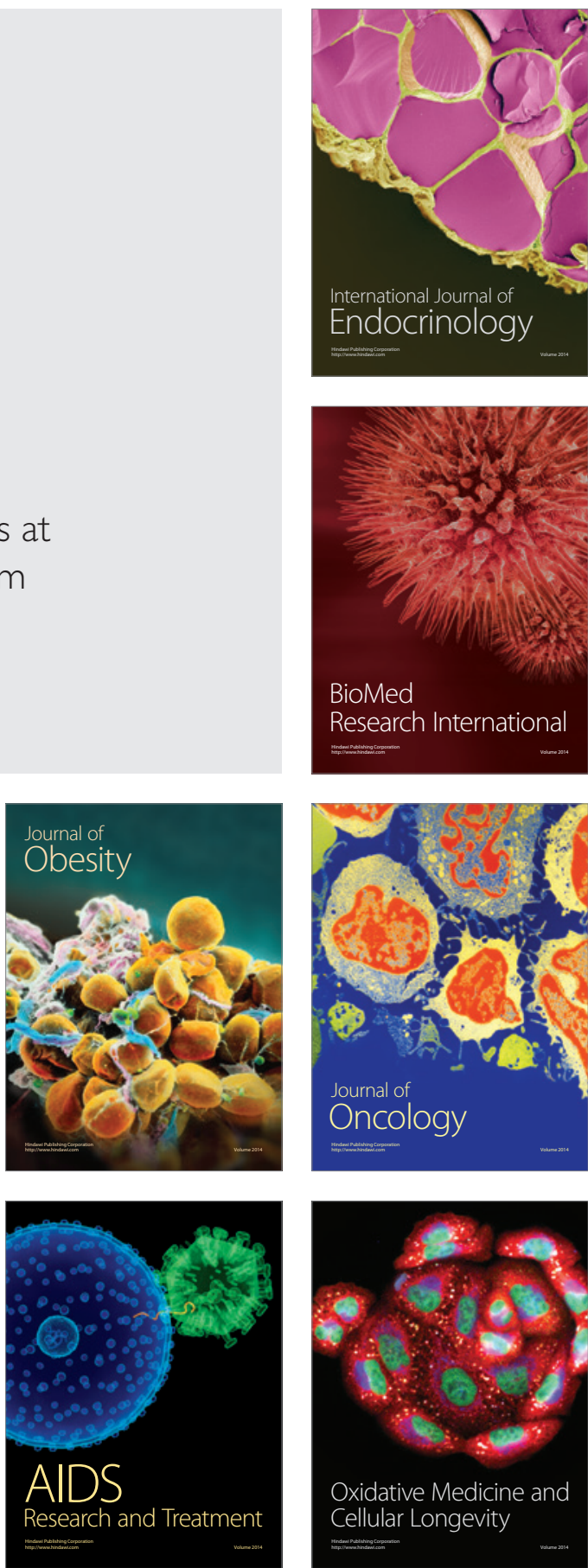